\title{
A Review on Friction Stir Welding of Steels
}

\author{
Dhanesh G Mohan and ChuanSong Wu* (1)
}

\begin{abstract}
Friction Stir Welding (FSW) is the most promising solid-state metals joining method introduced in this era. Compared to the conventional fusion welding methods, this FSW can produce joints with higher mechanical and metallurgical properties. Formerly, FSW was adopted for low melting metals like aluminum alloys. In recent years it has made significant progress in friction stir welding of steels since unfavourable phase transformations occurred in welds due to the melting of the parent and filler metals in fusion welding can be eliminated. The main advantage of FSW over traditional fusion welding is the reduction in the heat-affected zone (HAZ), and the joints exhibit excellent mechanical and corrosion resistance properties. This article reviews the progress in the relevant issues such as the FSW tool materials and tool profiles for joining steels, microstructure and mechanical properties of steels joints, special problems in joining dissimilar steels. Moreover, in-situ heating sources was used to overcome the main limitations in FSW of hard metals and their alloys, i.e., tool damages and insufficient heat generation. Different in-situ heating sources like laser, induction heat, gas tungsten arc welding assisted FSW for various types of steels are introduced in this review. On the basis of the up-to-date status, some problems that need further investigation are put forward.
\end{abstract}

Keywords: Friction stir welding, Steels, Microstructure, Mechanical testing, Hybrid welding

\section{Introduction}

Friction Stir Welding (FSW), as a solid-state welding process, can achieve the joining of metals below the melting point or in the plastic stage of the metals with the aid of a non-consumable tool [1]. Compared with the welds made by fusion welding processes, the friction stir welds have a more homogeneous grain structure and better mechanical properties like tensile strength, hardness, and toughness [2]. Friction stir welded specimens exhibit better corrosion resistance properties due to the homogeneous microstructure and narrow heat-affected zone. The feature of joining metals in the semisolids state helps this FSW method to join metals with different melting points like aluminium and copper. Nowadays, FSW has become one of the prevailing joining processes of aluminium alloys in the industry [3-5]. While considering hard metals like steel, FSW still does not accomplish the same feasibility in aluminium alloys [6, 7]. The limitations of friction stir welding on steels are as follows: (a)

\footnotetext{
*Correspondence: wucs@sdu.edu.cn

Institute of Materials Joining, Shandong University, Jinan 250016, China
}

a very high durable tool is required for welding steels, (b) the temperature produced by the tool pin and shoulder will not be sufficient to plasticize the metals, (c) welding speed cannot be attained as good as on aluminium alloys due to the high hardness of steels, (d) tool damage rate is very high, and (e) high flow stress is maintained by the hot steels while conducting FSW process, and which causes high contact stress and severe tool degradations [8]. Tool material like commercial pure Tungsten (CpW) or Polycrystalline Cubic Boron Nitride (PCBN) tools can survive these problems. Still, it increases the welding cost by eight times or even more while comparing to fusion welding.

Although the FSW tools for steel are expensive, friction stir welding of steel has numerous advantages compared to conventional fusion welding methods. Some of them are as follows: (a) the heat-affected zone created by fusion welding is large, and this eventually decreases the strength and quality of the weld, (b) fusion welding requires a filler metal to join the base metals, where FSW does not require any filler metals at all, (c) to eliminate hydrogen embrittlement or porosity like defects, fusion welding requires shielding gas which will pollute the 
atmosphere highly, while FSW does not require any kind of shielding gases, (d) fusion welding arcs emit intense visible, ultraviolet, and infrared radiation which is very hazardous to the welder and nature, whereas FSW does not produce any harmful rays or FSW is a $100 \%$ ecofriendly joining process [9-11]. Moreover, fusion welding of martensitic steels is complicated, but for FSW, it is pretty easy.

To improve the welding efficiency and quality of steel, hybrid friction stir welding was invented. An additional heating source will combine with the conventional FSW for in-situ heating in hybrid friction stir welding. The best examples for such welding are laser-assisted FSW (LAFSW) and induction assisted FSW (IA-FSW) [12, 13]. These methods help to in-situ heat the metals, and by this way, a higher welding speed will achieve; the softening of metal before plunging the tool helps reduce tool damage rates, and tools like high-speed steel tungsten carbide were capable of welding steels [14]. In these methods, the temperature requires to weld steel ranges from 500 ${ }^{\circ} \mathrm{C}$ to $1100{ }^{\circ} \mathrm{C}$. The microstructure analysis of such joints proved that the specimen has a fine grain structure and better mechanical properties than fusion welding [15]. These researches show that FSW on steel became much cheaper and commercial, like FSW on aluminium alloys.

This article reviews the current research and advancements in friction stir welding of steels and determines all the constraints faced in this present scenario.

\section{FSW Tools for Joining Steels}

The tool materials widely used for FSW are high-speed steel (HSS). Soft metals like aluminium, copper and their alloys can often be welded by this kind of tool [16-18]. For overcoming tool wear, process parameters optimization is mandatory [19]. In welding steels, HSS tools are incapable because they cannot produce the required temperature, withstand the elevated temperature of about $950{ }^{\circ} \mathrm{C}$, and resist the abrasive wear [20-22]. The tools for joining steels must tolerate all kinds of wear, have high strength and hardness, and have fracture toughness. Considering all these properties, the tool materials used nowadays are Commercially pure Tungsten $(\mathrm{Cp}-\mathrm{W})$ and Poly Crystalline Cubic Boron Nitride (PCBN).

\subsection{Refractory Metals as FSW Tools}

Refractory metals are the kind of metals that exhibit high melting points and wear resistance. The refractory metal tool cannot be fabricated using conventional metal-based forming techniques due to its high melting point [23]. The method adopted for making refractory metal tools is metal injection moulding. Due to this tedious processing, the metal cost will be much higher compared to HSS tools. Some of the essential refractory metal FSW tools

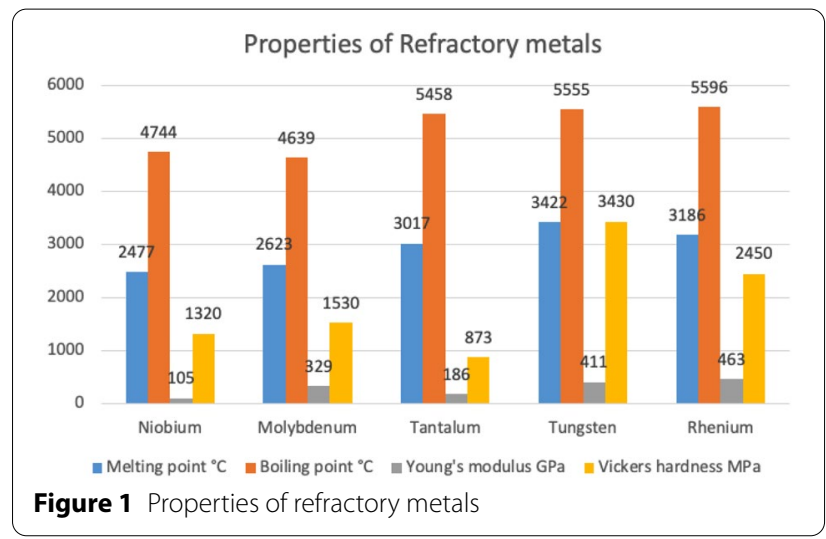

used nowadays are silicon nitride, tungsten carbide, tungsten lanthanide, and tungsten carbide cobalt alloy [24, 25]. Figure 1 shows the properties of refractory metals.

In the initial stages of welding steel through FSW, molybdenum and tungsten tools were adopted. The main limitation of these FSW tools is that they are fractured and deformed during plunging into steels [26]. The deformations are happened due to the high axial force while plunging the tool into the steels and high ductile-to-brittle transition temperatures of the tool material. Due to these all problems, these metals were replaced by a new refractory tool material, tungsten-rhenium (W-25\%Re). Comparing with the molybdenum and tungsten, tungsten-rhenium alloy exhibits less ductile-to-brittle transition temperatures due to the alloying element rhenium and has better wear resistance, too [27, 28]. Moreover, the damages happening to the tool during welding of steels are still not recovered fully.

\subsection{Synthetic Material as an FSW Tool}

The Polycrystalline Cubic Boron Nitride (PCBN) is one of the best Carbon Boron Nitride tools commonly used for friction stir welding, machining and cutting operations. By utilizing a sintering or frottage method, the PCBN can be fabricated [29-31]. For this sintering process, high temperature and pressure are necessary, along with binder phases. The binder phase includes metals like nickel and copper and ceramics like aluminium oxide, titanium carbide, and titanium nitride [32-35]. Figure 2 shows the properties of PCBN.

PCBN provides high hardness, and diamond is the only hard material available which offers more hardness than PCBN. Comparing with diamond, PCBN can withstand very high temperatures. PCBN also resists thermal shock, chemical wear and offers high toughness [36-39]. Due to these abilities, PCBN tools were accepted mainly for machining areas, including friction stir welding. Numerous researches are conducted on PCBN tools. It primarily 


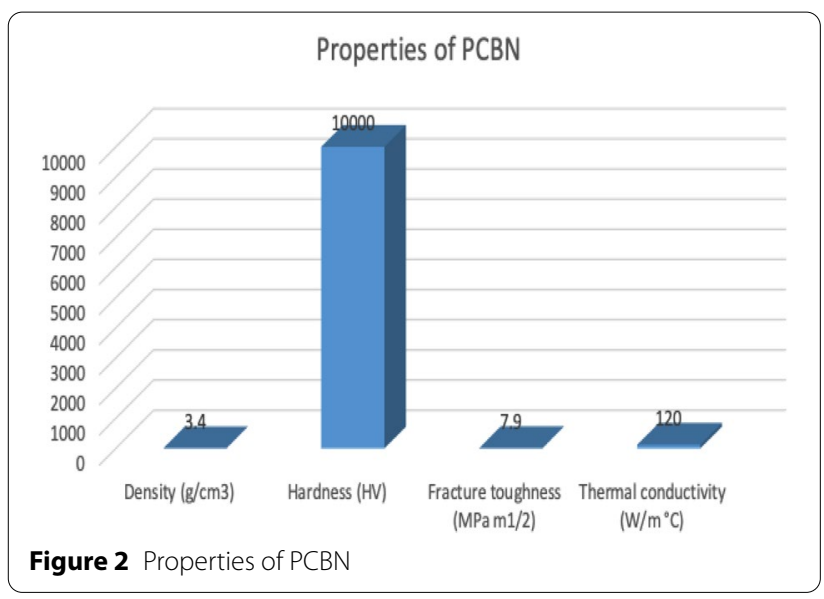

concentrates on the pin and shoulder profiles and how it affects the weld's mechanical properties [40].

The studies show that PCBN can successfully implement for alloy steels and stainless steels, like austenitic stainless steel, ferritic stainless steel, martensitic stainless steel, and duplex stainless steel. Comparing with the refractory metals FSW tools, PCBN provides a much better joint with uniform microstructures [41, 42]. Many researchers took PCBN-tungsten alloys tools to weld less hard steel alloys with a thickness of up to $12 \mathrm{~mm}$. While using the same alloys, deformations were still happening to these tools [43]. Nowadays, superalloys tools are primarily considered. The superalloys mainly used for FSW are cobalt or nickel-based ones [44-46].

Moreover, these are not sustainable remedies for preventing the fracture of tools, improving joints' strength, and making the steel welding process cheaper. The current research shows that the better option is to adopt a hybrid welding technique. By utilizing such methods, conventional tools can weld hard alloys, such as the tungsten carbide tool for AISI 410 stainless steel plates [47].

\subsection{Tool Profile}

The tool profile or tool geometry critically influences the weld quality and the tool wear rate. The tool profile helps the FSW process in the followings ways: (a) to generate accurate temperature in welding, (b) to create the same axial force to the weld region, (c) to achieve good welding speed, and (d) to gain proper metal flow in the stir zone and to gain homogenous grain structure $[48,49]$. The stir zone's plastic deformation rate also depends on the tool profile, not on the tool rotation rate and welding speed. The significant factors that need to consider before design a tool are (a) the thickness of the base plate, (b) the kind of base metal, whether it is a soft or hard metal, and (c) the tool material [50]. While designing a tool, the vital factors that need to consider

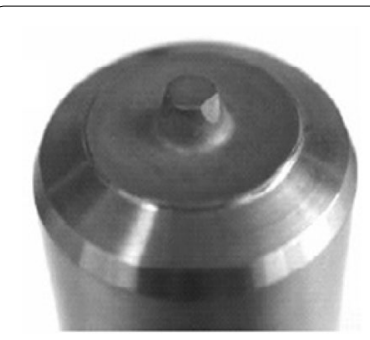

(a)

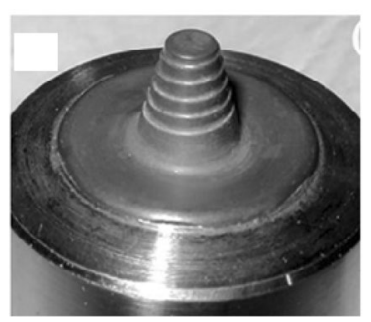

(b)
Figure 3 Examples of tool profiles: a Tapered PCBN tool, b Convex scrolled shoulder + step spiral pin tool [62]

are the pin diameter \& profile and the shoulder diameter \& profile. The shoulder profile plays a crucial role in FSW. The area needs to heat, and the heat generated for welding depends on the shoulder profile and diameter [51-53]. With increasing the shoulder diameter, the heating area will also get increased. The unwanted increment in the shoulder size leads to an increase in the heat-affected zone [54].

Ultrahigh carbon steel with a thickness of $2.3 \mathrm{~mm}$ was welded successfully with the aid of a tapered PCBN tool (shoulder diameter $12 \mathrm{~mm}$, and pin length $2 \mathrm{~mm}$, diameter at the top $4 \mathrm{~mm}$ and bottom $5.8 \mathrm{~mm}$ ) $[55,56]$. The results have shown that the fine grain structure was visible in the thermomechanical affected zone due to continuous dynamic recrystallization. An NSSC 270 super austenitic stainless steel with a thickness of $6 \mathrm{~mm}$ was welded by using a convex scrolled shoulder + step spiral pin tool at a tool rotation speed of 400 and $800 \mathrm{r} /$ min [57-60]. At $400 \mathrm{r} / \mathrm{min}$, the strength and ductility of the joint were similar to the base metal, while more intermetallic phases were formed at $800 \mathrm{r} / \mathrm{min}$, which resulted in weak joint strength. Figure 3 shows the tapered PCBN tool and the convex scrolled shoulder + step spiral pin tool.

A SAF 2507 grade super duplex stainless steel of thickness $1.5 \mathrm{~mm}$ was butt welded by PCBN tool with a concave shoulder (diameter $25 \mathrm{~mm}$ ) and tapered pin (length $3.8 \mathrm{~mm}$ ) [61-63]. The results show that the joint possesses the same strength as the base metal, and the specimen was broken at the retreating side near the thermomechanical affected zone and retreating side [64, 65]. An AISI 304L stainless steel of thickness 3.4 $\mathrm{mm}$ was welded using a tungsten alloy tool with a concave shoulder profile (shoulder diameter $10.2 \mathrm{~mm}$ ) and a cylindrical pin profile (pin length of $2.3 \mathrm{~mm}$ ) [66-68]. The result shows that a joint efficiency attained ranges from $80 \%$ to $98 \%$, and the ultimate tensile strength is near to the base metal. After successful welding, tool wear is found at the pin tip and shoulder edge; these 


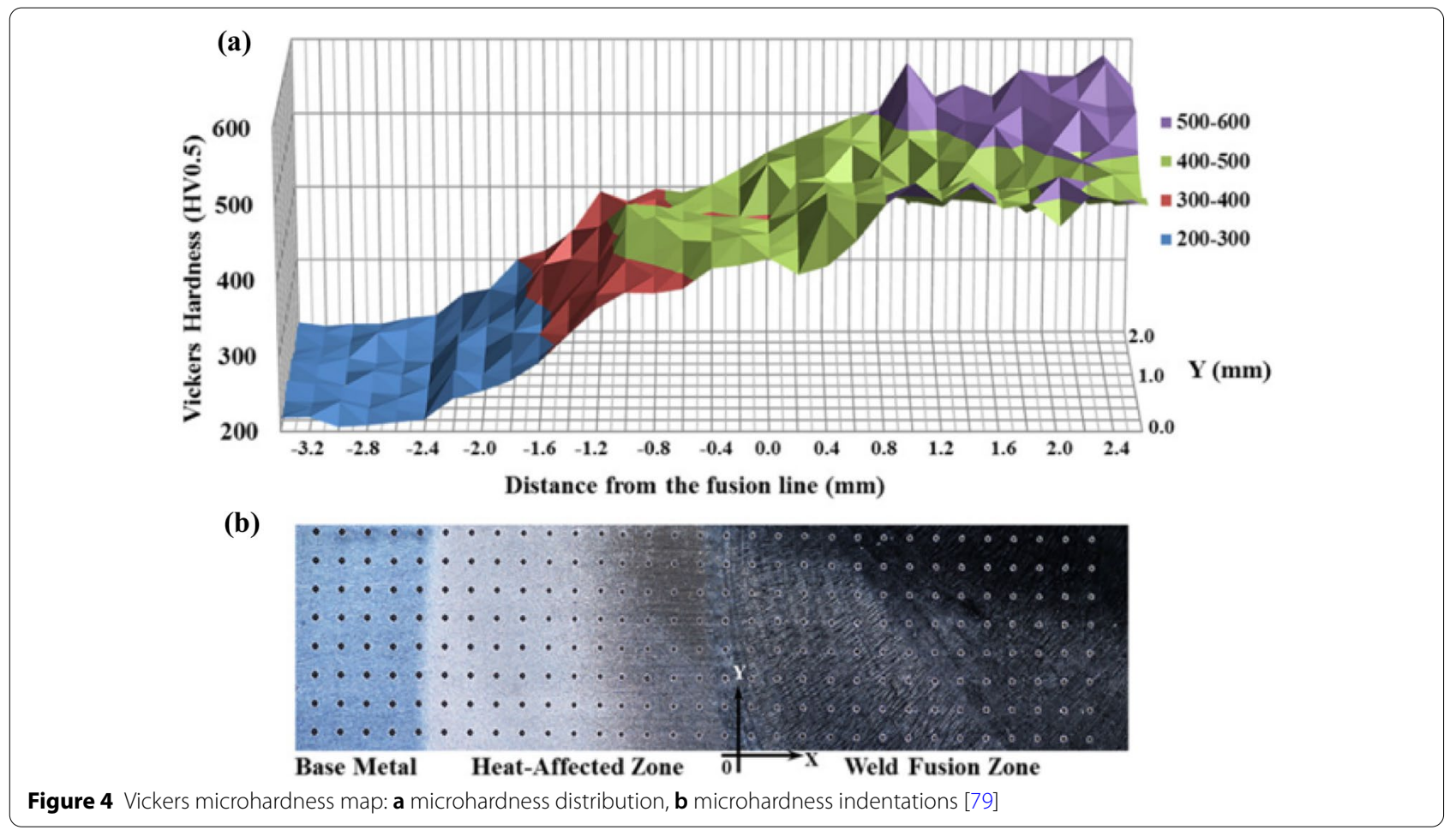

kinds of wear are mostly happening to the tungsten alloy tools due to their inability to withstand large axial force in welding $[69,70]$.

An AISI 410 martensitic stainless steel plate of thickness $3 \mathrm{~mm}$ was successfully welded by induction assisted FSW. The tool used was tungsten carbide $(25 \mathrm{~mm}$ shoulder diameter, $2.6 \mathrm{~mm}$ pin length and $5 \mathrm{~mm}$ pin diameter, hexagonal pin profile) $[71,72]$. The strength gained was close to the base metal that is $462 \mathrm{MPa}$, and the specimen exhibited a much higher corrosion rate of 2.79757 $\mathrm{mm}$ /year, which is better than the corrosion rate of base metal. The in-situ heating helped the tool propagate and stir well in the stir zone and achieved a homogeneous fine grain structure than the base metal [73]. An S45C steel plate was successfully welded by using laser-assisted FSW. The tool used for this welding was a tipped tungsten cobalt alloy tool. The main advantage shown in this process was the high welding speed, $800 \mathrm{~mm} / \mathrm{min}$. In the conventional FSW method, it was about $400 \mathrm{~mm} / \mathrm{min}$ $[74,75]$. This method made a tensile strength of joint close to the base metals, and the specimen failure has happened in the base metal area.

\section{Microstructure and Mechanical Properties \\ 3.1 Mechanical Properties}

The prime aim of a metal joining is to achieve excellent mechanical properties like tensile strength and hardness. Nowadays, a lot of research has been conducted to enhance the joints' mechanical properties [76-78]. Many studies show that most friction stir welded steel joints achieve mechanical properties close to the base metals.

The friction stir welding on modified $9 \mathrm{Cr}-1 \mathrm{Mo}-\mathrm{V}-\mathrm{Nb}$ steel was done successfully, and the microhardness distribution across the weldment cross-section was studied. The weld zone possessed a different range of microhardness from the heat-affected zone to the stir zone due to varied heat generated in each area [79]. The weld is shown the peak microhardness of 503 HV0.5. The formation of fresh martensite resulted in this microhardness. Relatively lower microhardness was found in the tempered region. Due to the tempering effect, the microhardness found was 482 HV0.5. Because of the martensitic substructure, the heat-affected zone shown a microhardness of 417 HV0.5 [80, 81]. Figure 4 shows the Vickers microhardness map at the cross-section of friction stir welded P91 steel joint.

An austenitic stainless steel grade AISI 410 was successfully welded by using the tungsten lanthanum oxide tool. The influence of the tool tilt angle was studied. When a tool tile angle of $1.5^{\circ}$, with the parameter combination of tool rotation speed $600 \mathrm{r} / \mathrm{min}$, welding speed 45 $\mathrm{mm} / \mathrm{min}$, and axial load $11 \mathrm{kN}$, was used, the best results were achieved. The tool tilt angle enhanced the weld's plasticization so that a uniform microstructure throughout the weld was obtained [82-85]. The yield strength of the weld joint was $605 \mathrm{MPa}$, which means the weld joint 
can achieve a strength of $96 \%$ of the base metal. An average microhardness attained in the stir zone was $230 \pm 5$ $\mathrm{HV}$, and this microhardness value is higher than the thermo-mechanically affected zone.

DP700 high strength steel was butt welded with two constant parameters and one varying parameter. The tool rotation speed was constant at $800 \mathrm{r} / \mathrm{min}$ and tool tile angle at $3^{\circ}$, while the welding speed varied from $100 \mathrm{~mm} /$ $\mathrm{min}, 150 \mathrm{~mm} / \mathrm{min}$, and $200 \mathrm{~mm} / \mathrm{min}[86,87]$. A parameter combination of $800 \mathrm{r} / \mathrm{min}$ tool rotation speed, 150 $\mathrm{mm} / \mathrm{min}$ welding speed and $3^{\circ}$ tool tilt angle provided the best results. The mechanical properties like tensile strength and microhardness were studied. The stir zone had an average microhardness of $395 \mathrm{HV}$, while the base metal had a microhardness of $275+3 \mathrm{HV}$. The improved microhardness gained in the stir zone is due to the cooling rate and grain refinement. Under the same parameter combination, the tensile strength of the joint was $687 \mathrm{MPa}$, which means the weld joint offers $91.7 \%$ more strength than the base metal.

FSW welded a steel plate of IS 2062, and a mechanical test like microhardness was carried out. The average microhardness found in the base metal and stir zone was $143 \mathrm{VN}$ and $182 \mathrm{VN}$ at $200 \mathrm{~g}$ load. The increase in the stir zone's microhardness was due to the grain refinement and cooling rate [88-91]. The result has also shown that grain refinement helped to increase the tensile strength of the joint.

\subsection{Microstructure Evaluation}

The weld structure analysis helps to study and understand the material flow and microstructure formation. By evaluating these things, the weld defects can be easily found out. The grain structure evolution during welding can be examined by comparing the grain structure of welded specimens with that of the parent metal. The grain's homogeneity in the weld area can be determined [92-95].

Currently, many types of research are conducted in the FSW of steels. The results show that many factors affect the microstructure formation in friction stir welding of steels. Some of the significant parameters affecting the microstructures are (a) tool rotation speed, (b) welding speed, (c) axial force, (d) tool profile, and (e) tool tilt angle. The common thing related to these parameters is the amount of heat generated by these process parameters, while welding significantly affects microstructure evolution $[96,97]$. The material flow in the stir zone predominantly depends on the tool and its profile. The tool shoulder influences the top layer material movements, while the pin profile and tip control material movements at the intermediate and lower portions [98-101]. Figure 5 shows the tool influencing areas during FSW.

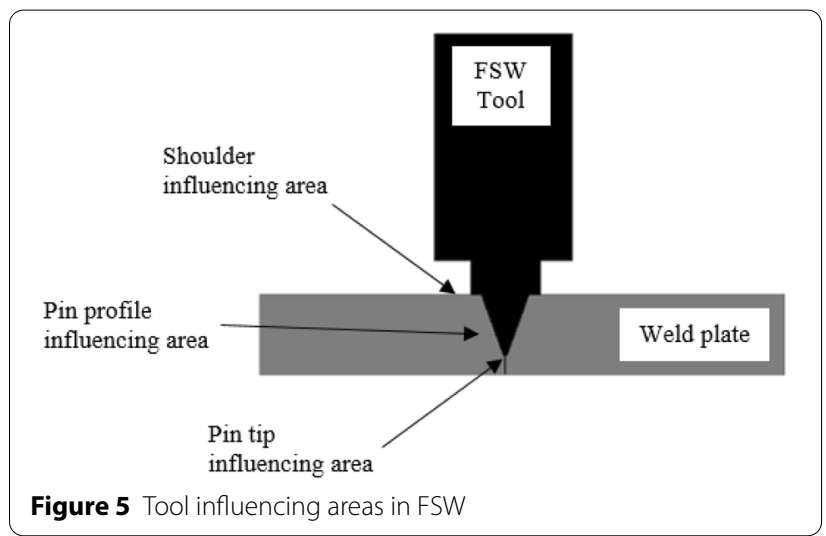

A butt joint was configured using DP 700 grade stainless steel. The microstructure evaluation showed that the stir zone's grain structure was transformed into a single-phase austenite structure at a $100 \mathrm{~mm} / \mathrm{min}$ welding speed. The temperature generated at this time was $885^{\circ} \mathrm{C}$ [102-104]. Increasing the welding speed to 150 $\mathrm{mm} / \mathrm{min}$ and $200 \mathrm{~mm} / \mathrm{min}$, a dual-phase ferrite-austenite area was found in the bottom regain. The top and the middle portion remained the same single phase austenite structure. The temperatures generated in welding at $150 \mathrm{~mm} / \mathrm{min}$ and $200 \mathrm{~mm} / \mathrm{min}$ were $813{ }^{\circ} \mathrm{C}$ and 731 ${ }^{\circ} \mathrm{C}$, respectively [105]. The study has shown that the high welding speed led to the formation of a fine-grain structure with high hardness in the weld region. The correlation of temperature and welding speed in the microstructure change in DP 700 stainless steel friction stir welding was addressed well.

An AISI 316L stainless steel was welded successfully using the FSW method, and a nearly fine grain structure was found in the stir zone. The same grain structure was visible in the hot working process of AISI 316L stainless steels, and this is due to the low stacking fault energy of the austenitic steels [106-108]. The results showed that the weldment had a higher strain rate than the base metal's critical strain rate due to the displacement density across the grain boundaries and the strain-free nucleated grains.

Figure 6 presents the macrographs of the weld zone made at three different tool tilt angles. There are mainly four zones visible in a friction stir weld specimen, i.e., the base metal (BM), heat affected zone (HAZ), thermo-mechanically affected zone (TMAZ), and the stir zone (NZ) $[109,110]$. In Figure 6, very small or no $\mathrm{HAZ}$ is visible, revealing that the heat generated during welding was optimum. The tool shoulder diameter on the joint surface and the tool pin diameter towards the plate's bottom was roughly the same as the stir zone's volumetric size. 

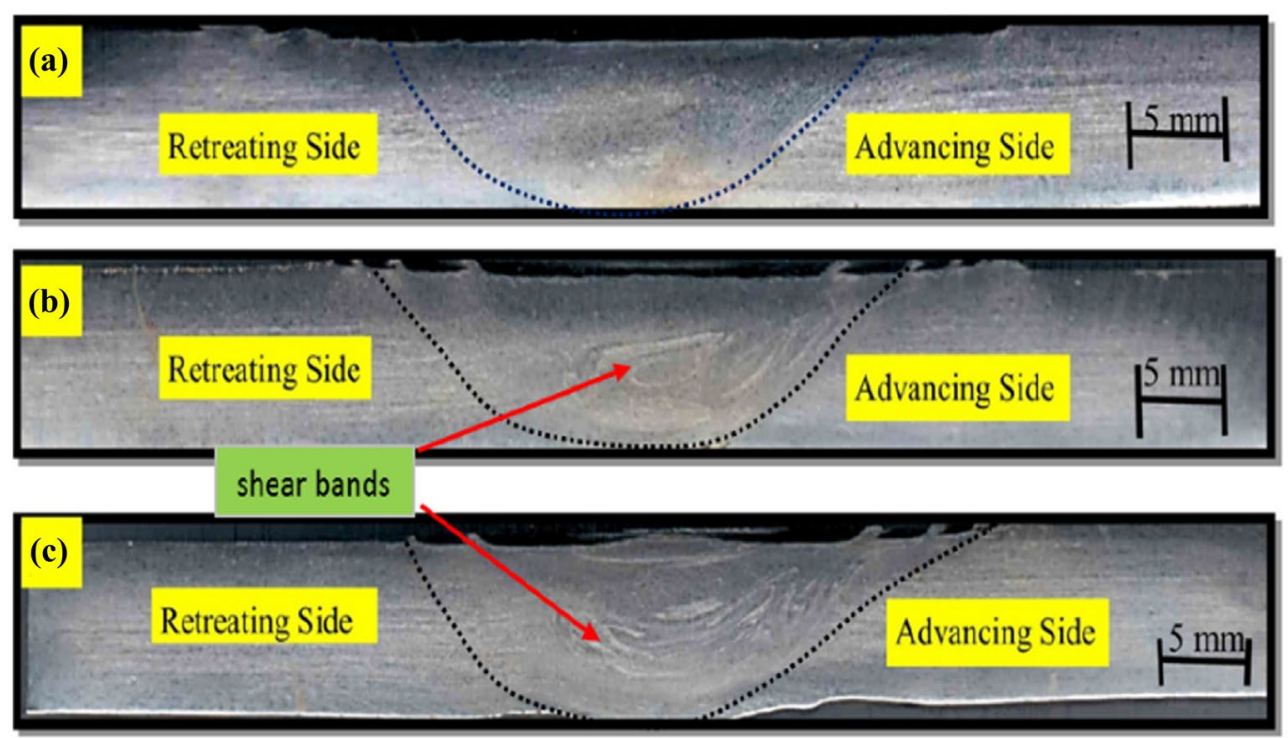

Figure 6 Macrographs of FSW welds: $\mathbf{a} 0^{\circ}$ tilt angle, $\mathbf{b} 1.5^{\circ}$ tilt angle, $\mathbf{c} 3^{\circ}$ tilt angle [110]

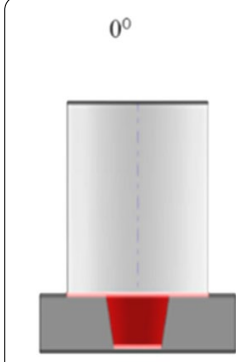

(a)

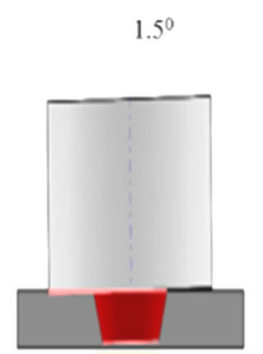

(b)

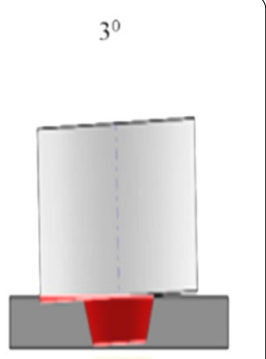

(c)
Welding direction

Figure 7 Schematic representation of dynamic stir zone: $\mathbf{a} 0^{\circ}$ tilt angle, b $1.5^{\circ}$ tilt angle, $\mathbf{c} 3^{\circ}$ tilt angle [1 10]

Figure 7 is a schematic diagram illustrating the dynamic stir zone volume for three different tool tilt angles. When the tool tilt angle is increased, the stir zone's dynamic volume is raised a little [111-114]. Under three levels of tool tilt angle $0^{\circ}, 1.5^{\circ}$ and $3^{\circ}$, the dynamic volume is $104.64 \mathrm{~mm}^{3}, 116.24 \mathrm{~mm}^{3}$ and 127.84 $\mathrm{mm}^{3}$, respectively.

It is visible that at $0^{\circ}$ tool tile angle, the stir zone's volume and the tool shoulder diameter are similar due to perfect contact between the tool shoulder and the weld surface [115-117]. Hence, the physical contact changes when it comes to $1.5^{\circ}$ and the $3^{\circ}$ tool tilt angle, and the dynamic stir zone also increases. The shear band formation in the weld zone can be explained by the rise in the stir zone's dynamic volume, where the formation of the nugget zone with an incline top flow arm is more comprehensive when moving towards the advancing side $[118,119]$. This shear band is very narrow and defect-free. One of the disadvantages of this shear band is that they are inelastic and does not undergo deformation at a high strain rate.

Figure 8 shows the AISI 316L stainless steel and friction stir weld joint's micrograph at three different tool tilt angles. It indicates that the tool tilt angle significantly affects forming microstructure and material flow in the weld zone. A temperature of $865^{\circ} \mathrm{C}$ was attained by the $3^{\circ}$ tool tilt angle, which is sufficient to produce a sound joint in AISI 316L stainless steel. The heataffected zone generated was significantly less [120122]. Moreover, a fine grain structure was achieved. A temperature of $968{ }^{\circ} \mathrm{C}$ was developed by $0^{\circ}$ tilt angle, and the increase in heat led to the rise in the heataffected zone and some coarse grain structure in the stir zone. While adopting a tool tilt angle of more than $3^{\circ}$, the tool cannot produce sufficient heat and results in poor joint strength [123].

The optical microscope also reveals that due to the strong dynamic recrystallization in the stir zone by different tool tilt angles of $0^{\circ}, 1.5^{\circ}$, and $3^{\circ}$ resulted in the formation of grains of size $8 \pm 3 \mathrm{~mm}, 5 \pm 2 \mathrm{~mm}$ and $6 \pm 2 \mathrm{~mm}$, respectively. Due to the discontinuous dynamic recrystallization process, approximately equiaxed refined grains were visible in the stir zone. Similar recrystallization was observed in all medium to low stacking fault energy materials like AISI 316L [124-126]. 


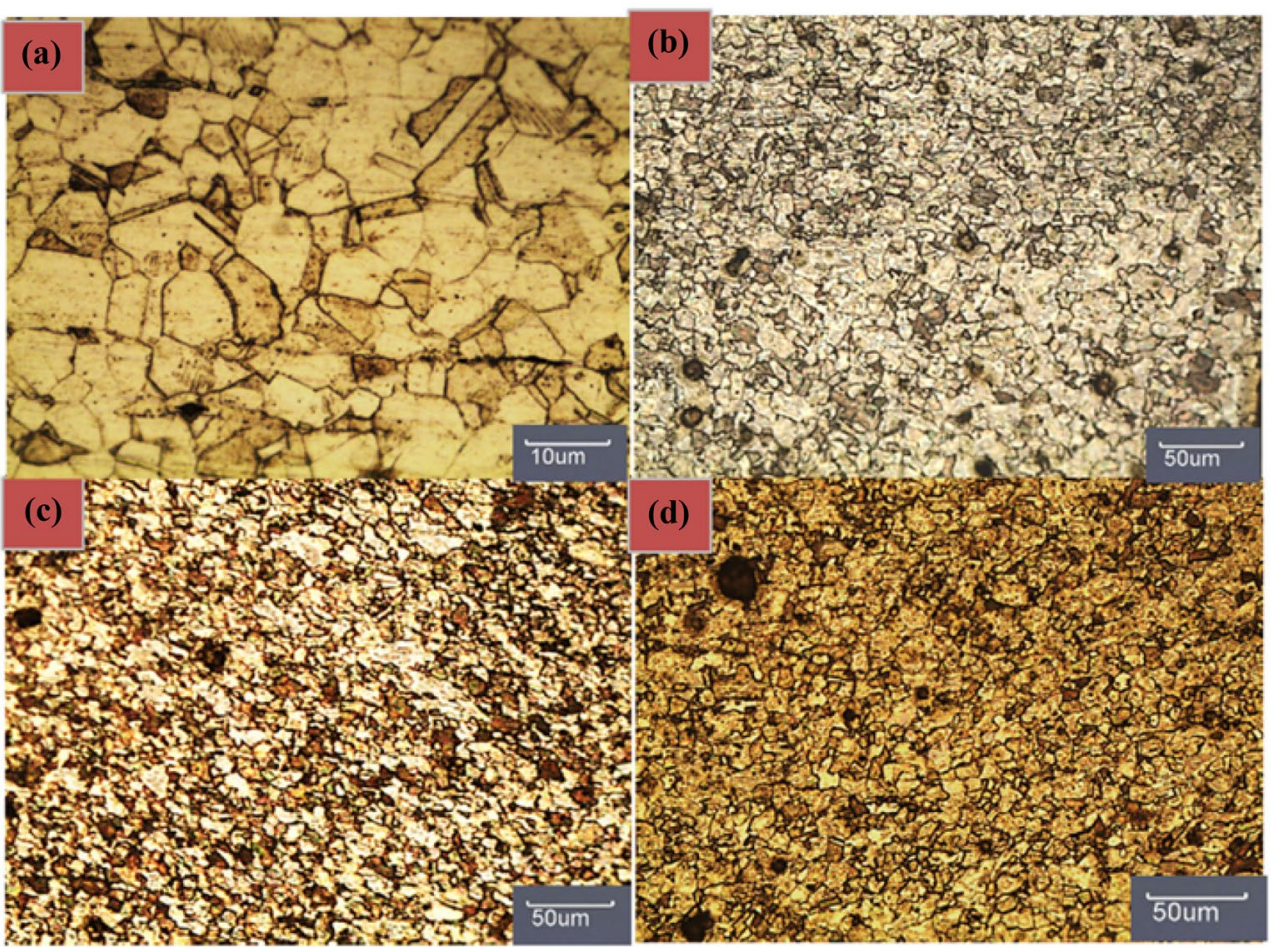

Figure 8 Micrograph of AISI 316L stainless steel with friction stir welded specimen at three different tool tilt angles: a Base metal, $\mathbf{b}$ at tilt angles of $0^{\circ}, \mathbf{c}$ at tilt angles of $1.5^{\circ}, \mathbf{d}$ at tilt angles of $3^{\circ}[124]$

\subsection{Surface Defects}

Some typical surface defects that happen to the friction stir welded stainless steels with similar and dissimilar metals are rough texture, surface cracks, and grooves. These surface defects are mostly related to poor plasticization or over plasticization that happens to the joint surface. These plasticization issues are majorly associated with the welding parameters like welding speed, tool rotation speed, axial force/plunge depth, or related to the pin and shoulder designs of the FSW tool. Two dissimilar steel grades of DH36 and EH46 were joined by using the FSW method [127]. The experiment reveals that surface defects like microcracks were visible in the weld surface. Figure 9 shows the microcracks propagated from the top surface of FSW DH36 between the steady-state and the plunge regions. Figure 9(a) low magnification, Figure 9(b) high magnification. The sample was cut in the direction of the weld line.

The reason for forming this microcrack in the bimetallic region is related to the lack of materials flow. It is directly related to the welding speed and tool rotation speed. Microcracks were prolonged when the welding speed exceeded $400 \mathrm{~mm} / \mathrm{min}$ and a tool rotation speed of $550 \mathrm{r} / \mathrm{min}[128,129]$. A temperature of $1250^{\circ} \mathrm{C}$ was found when the tool rotation speed went beyond $550 \mathrm{r} / \mathrm{min}$; this led to the elemental precipitation of TiN and elemental segregation of $\mathrm{Mn}, \mathrm{Si}, \mathrm{Al}$ and $\mathrm{O}$ between the bimetallic region. This prevented the material flow, resulted in the formation of microcracks, and eventually decreased the mechanical properties of the joints.

Figure 10 shows the different characteristic defects that happen while joining dissimilar stainless steel using FSW. Most of the defects are related to the tool geometry or material flow [130-132]. Fusion defects that happened due to the lack of tool penetration or improper seam tracking are considered tool geometric defects, and the flow-related defects are related to the heat generation in the weld zone. When the heat generated at the weld zone is very high, the weld zone becomes over plasticize and results in the flash formation, which leads to the surface galling and nugget collapse [133, 134]. The insufficient material flow was visible when the heat generated while welding was too low, and this resulted in the lack of surface fill. This lack of surface fill forms defects like consolidation defects on the advancing side due to increasing forge force and wormholes [135-137].

While adopting the optimum process parameters for joining steels with the FSW method, the flow-related defects happen at a temperature where stick-slip wiping flow occurs, and material flowing from the region ahead 


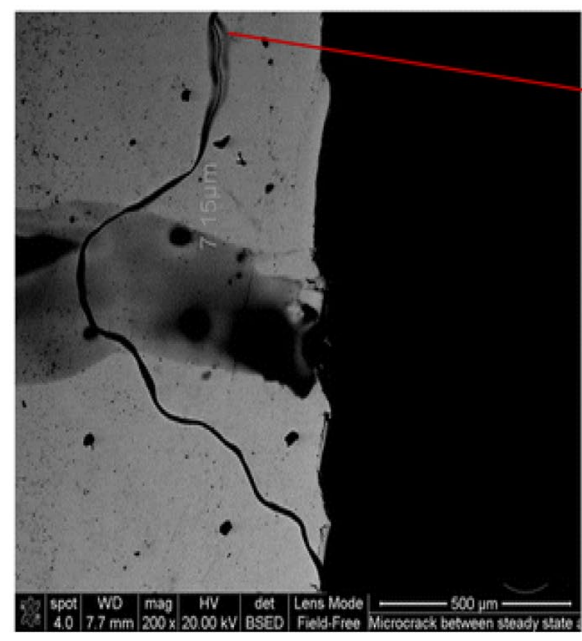

(a)

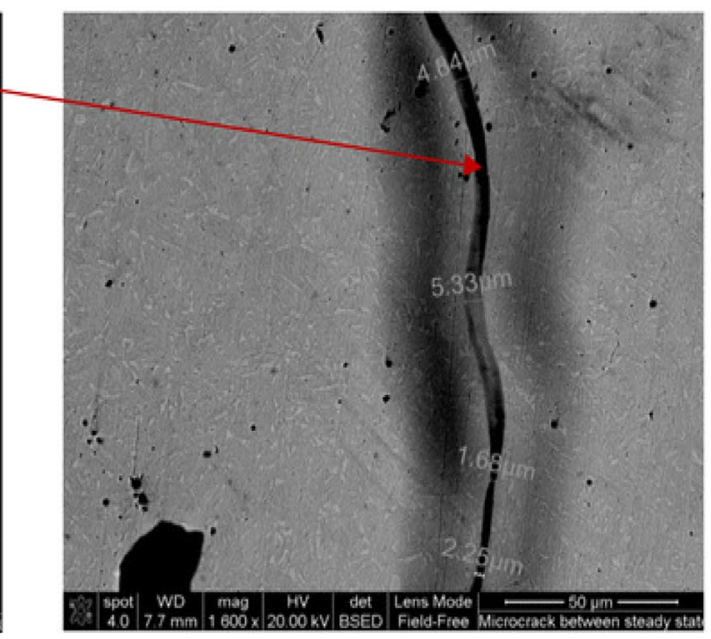

(b)

Figure 9 Microcracks prolonged on the DH36 and EH46 FS-Weld region started from the top surface: a low magnification, b high magnification [127]

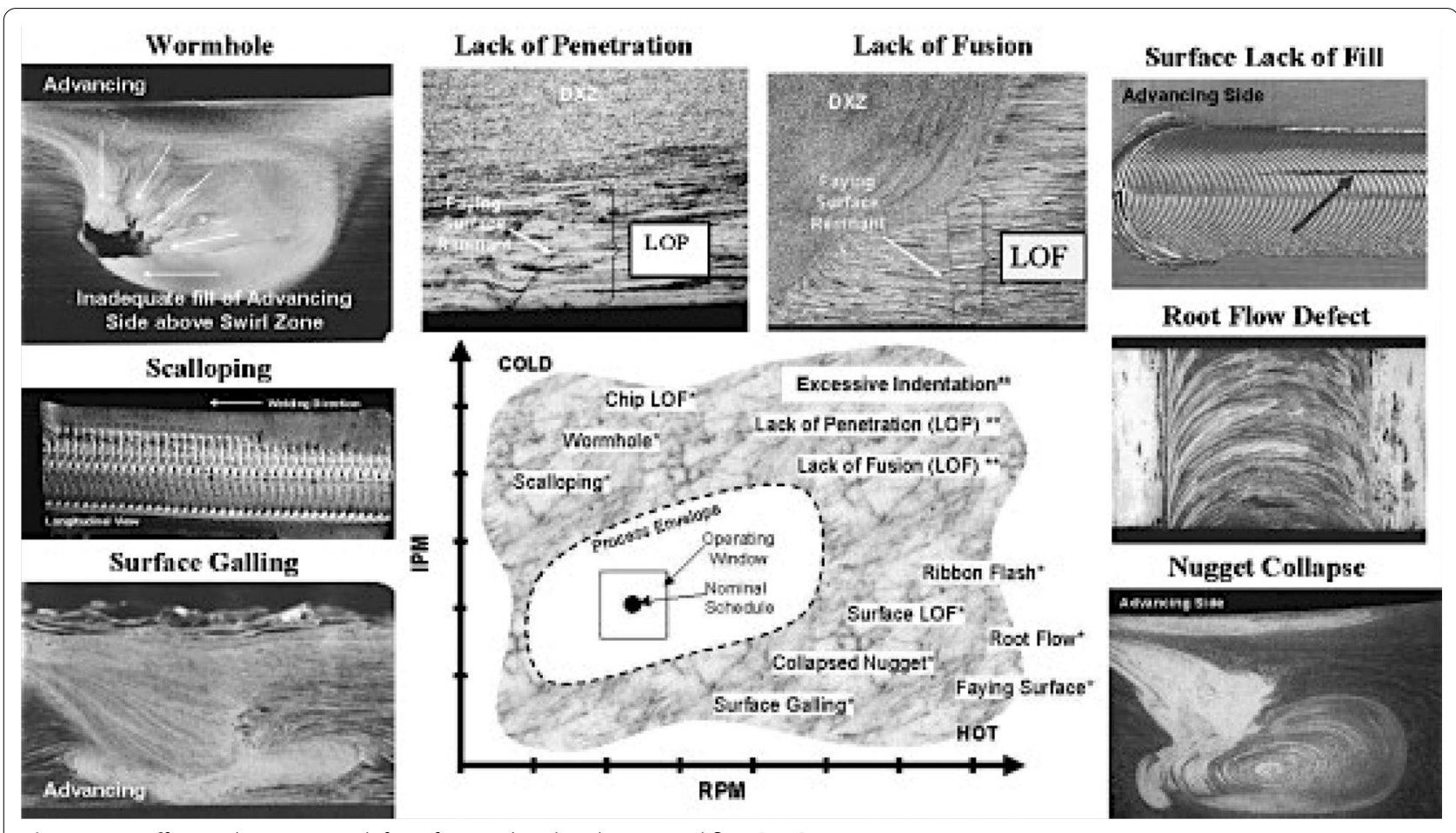

Figure 10 Different characteristic defects forms related to the material flow [130]

of the pin tool can be eliminated [138]. Another common surface defect usually visible while joining hard metals like steel is surface groove defects. Figure 11 shows the surface groove defect on AISI 430 stainless steel weld surface.
This steady appearance of flat surface groove defects is formed in low pressure due to the insufficient axial force/plunge depth. Surface groove defects can be removed by sufficient axial force/plunge depth on the 


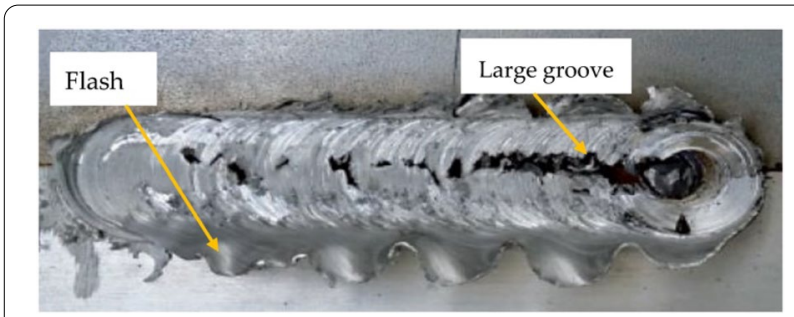

Figure 11 Surface groove defect in AISI 430 stainless steel joint [138]

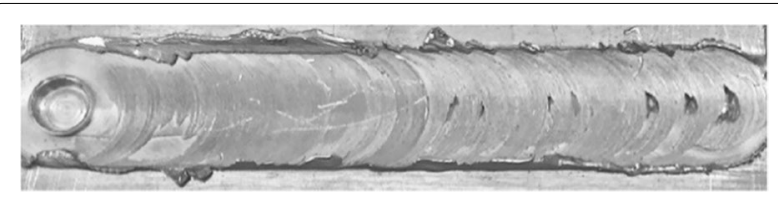

Figure 12 AISI 304 steel joint with high surface textures [142]

butting region [139, 140]. Moreover, to prevent surface groove defects, sufficient heat input is required.

The surface finish provided by the FSW joining method is related to the tool movements like welding speed and tool rotational speed [141]. The surface finish plays a vital role in the weld joint property; while the FSW tool rotates and moving along the butting surface, it leaves feed marks (onion rings) on the weld surface. If the welding speed is too high or the tool rotation is too low, rough surface textures form. These surface properties lead to higher surface stress concentration and eventually degrade the joints' mechanical properties, especially fatigue life cycle [142]. Thus, an FSW joint with a higher surface texture has a weak joint strength. Figure 12 shows the FSW joint fabricated with AISI 304 steel; high textures are visible on the weld surface.

\section{Friction Stir Welding of Dissimilar Steels}

The vital issue of fusion welding is its limitation to weld dissimilar metals and the heavy heat affected zone created in the joining process. Compared to fusion welding, the heat generation is significantly less in FSW. FSW can overcome the problems encountered by fusion welding due to its solid-state welding feature.

11 pct $\mathrm{Cr}$ ferritic/martensitic steel (PNC-FMS) and 316 austenitic stainless steel were successfully welded using the FSW process. AISI 316 was kept at the advancing side and the PNC-FMS at the retreating side for this welding. A defect-free joint was produced, but the two steel plates were not mixed well but interleaved a sharp zigzagging interface in the stir zone [143]. Besides, the robust interface did not act as a fracture site when a micro tensile test was conducted for the stir zone alone. The mechanical

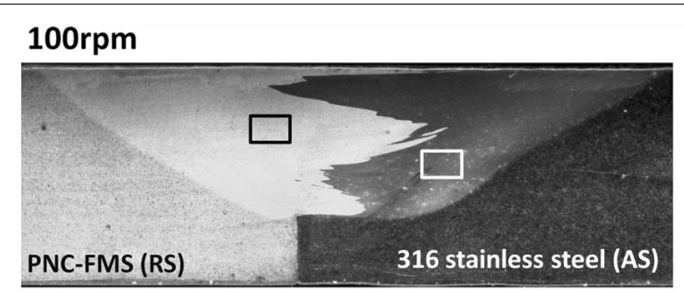

\section{0rpm}

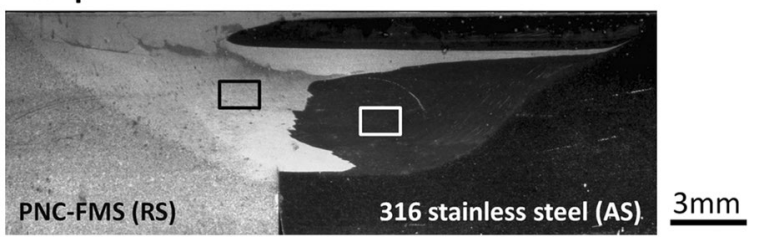

Figure 13 Transverse cross-section of the dissimilar joints [145]

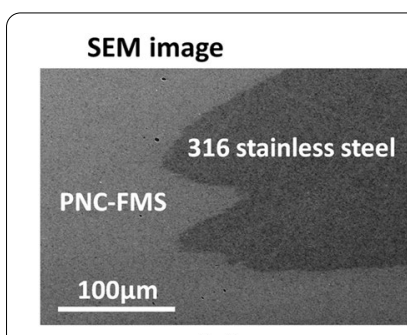

(a)

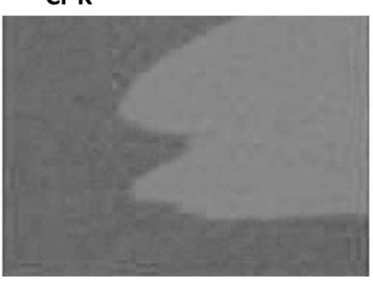

(c)

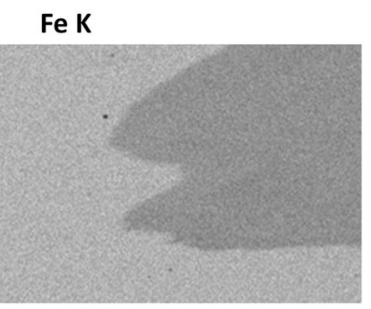

(b)

Ni K

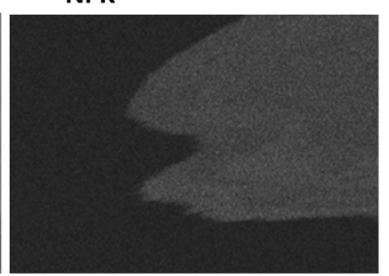

(d)
Figure 14 a SEM image, b Fe, c Cr, and $\mathbf{d} \mathrm{Ni}$ elemental maps [146]

property revealed by the specimen was much better than the base metals; this indicates that FSW can be feasible for sound welding in dissimilar metals, too [144, 145]. Figure 13 shows the transverse cross-section of the joints taken by optical microscopy, revealing that this joint does not have any weld defects, like tunnel defects, cracks and voids.

The scanning electron microscope image and the elemental mapping done by energy-dispersive $x$-ray spectroscopy (EDS) images are given in Figure 14. The lighter contrast in the EDS mapping images means the higher content, and the darker means, the lower content, respectively [146]. The specimen selected for elemental mapping was prepared at a tool rotation of $100 \mathrm{r} / \mathrm{min}$. 


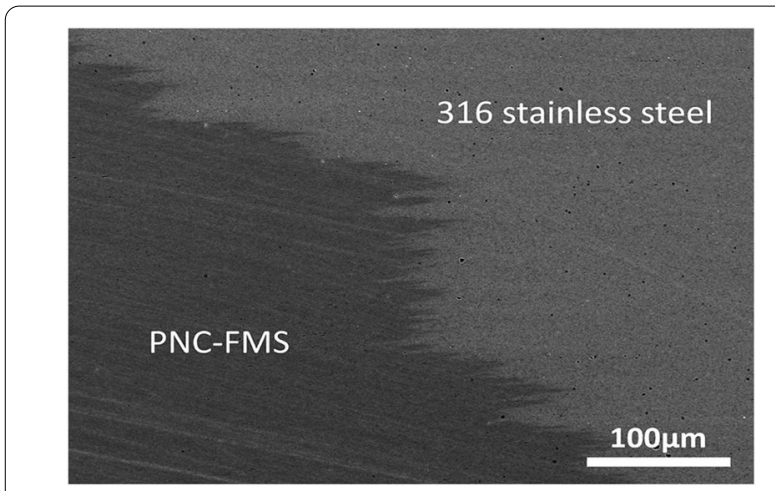

Figure 15 PNC-FMS and 316 stainless steel joint's SEM image [152]

The Fe in the 316 stainless steel side is lower when the $\mathrm{Cr}$ and Ni content is lower on the PMC-FMS side [147-151]. These distributed elements are separated along with the weld interface.

Figure 15 shows the magnified SEM image of the stir zone. There are no voids or reaction layers visible in it, and the interface's sharpness is very well observed [152]. A gradual change in $\mathrm{Cr}$ and $\mathrm{Ni}$ concentrations has occurred over the interface due to the diffusion of alloying elements during friction stir welding. In this experiment, the tool rotation speed of $100 \mathrm{r} / \mathrm{min}$ and $150 \mathrm{r} / \mathrm{min}$ exhibited similar results. The only difference was in the width of diffusion layers, and it was more prominent at the tool rotation speed of $150 \mathrm{r} / \mathrm{min}$ [153]. The results have proven that intermetallic bonding was successful in PNC-FMC and 316 stainless steel joints.

During friction stir welding of $\mathrm{F} 82 \mathrm{H}$ to 304 stainless steel, the shift in tool plunging prevented the intermixing in the nugget zone $[154,155]$, so the exact extent of mixing was in the stir zone not precise. Moreover, the welding conditions like tool profile and welding speed predominantly influence the nugget zone's grain formation [156-159]. Therefore, this research shows that any change in the plunging area may lead to kissing bonding or root defects.

In dissimilar welding of steel with other metals like superalloys [160], the melting point of these alloys is somewhat close. The super duplex steel SAF 2507 was friction stir welded with a nickel-based superalloy Incoloy 825 . A defect-free weld was fabricated by placing SAF 2507 on the advancing side and Incoloy 825 on the retreating side $[161,162]$. The microstructure analysis has shown that the thermo-mechanically affected side was from deformed austenite-ferrite grains of the SAF 2507 region and the elongated austenite at the Incoloy 825 region. Due to the subsequent refinement of the grain structure and dynamic recrystallization, the nugget zone shown the highest hardness.
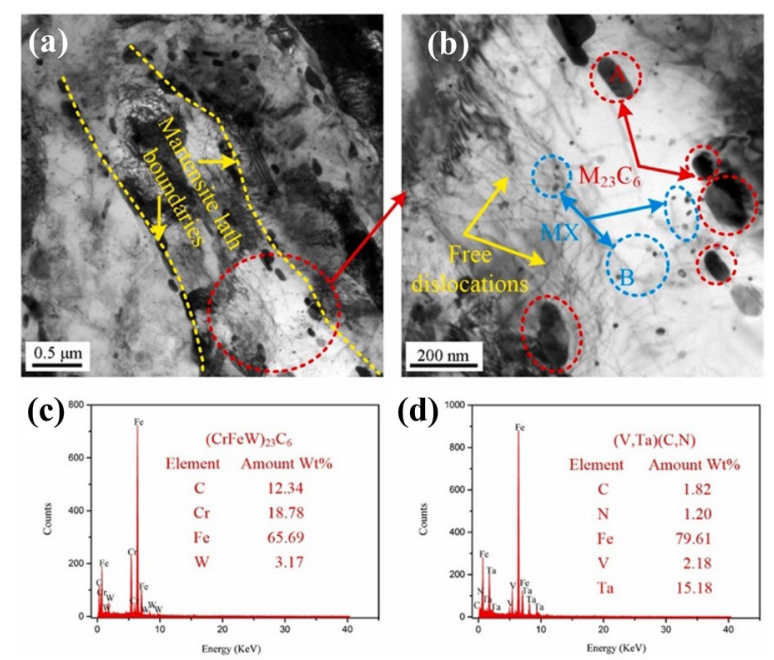

Figure 16 a Microstructure of BM using TEM, b local higher resolution microstructure of $B M, \mathbf{c} E D S$ graph of $A$ marked in Figure 13(b), d EDS graph of B marked in Figure 13(b) [173

In the medium carbon steel welding, carbon and chromium presence significantly affect the weld region's microstructure formation. The chromium content enhancement in the stir zone transformed the pearlite structure into a martensite structure [163, 164]. This transformation would increase the tensile strength and ductility of the joint. The carbon and chromium content also reduces the carbide precipitation in the stir zone due to martensite's auto tempering [165].

Due to the supercilious comprehensive properties of the reduced activation, ferritic/martensitic (RAFM) steels are broadly used in nuclear reactors as structural materials [166, 167]. An investigation was conducted to join the reduced activation ferritic/martensitic steel by friction stir welding. The quantitative relationship with microstructure generated in the stir zone and tensile strength was examined [168-171]. Moreover, the effects of post-weld tempering treatments were also studied. For this post weld tempering treatment, three different temperatures were adopted, i.e., $720{ }^{\circ} \mathrm{C}, 760{ }^{\circ} \mathrm{C}$, and $800{ }^{\circ} \mathrm{C}$, respectively [172]. The microstructure evaluation was conducted by using transmission electron microscopy (TEM), Electron backscatter diffraction (EBSD) and the Thermo-Calc Calphad software [173]. The matrix's precipitate number density, martensite lath width, geometrically necessary dislocation (GND) density, and solid equilibrium solubility of alloying elements were quantitatively analyzed.

The transmission electron microscope image of the RAFM steel is given in Figure 16(a) and 16(b). In Figure 16(a), a distinctive tempered martensitic microstructure is visible in it, and coarse M23C6 particles are seen in 

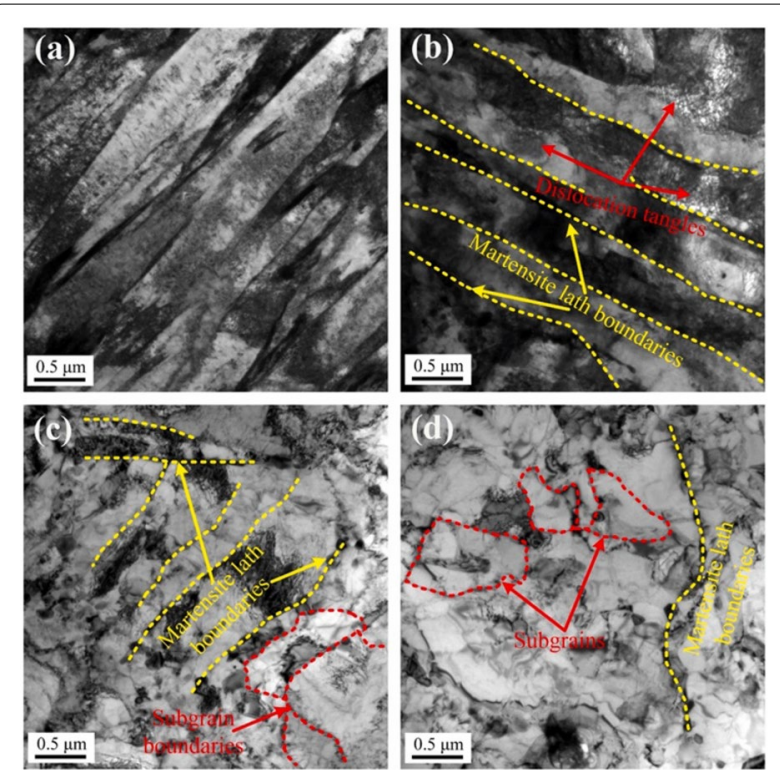

Figure 17 TEM micrographs of the SZ at different conditions: a SZ in the as-welded condition, $\mathbf{b}$ SZ tempered at $720^{\circ} \mathrm{C}$, $\mathbf{c ~ S Z}$ tempered at $760{ }^{\circ} \mathrm{C}$, d SZ tempered at $800^{\circ} \mathrm{C}[178]$

the martensite lath boundaries. In Figure 16(b) the inner area of the martensite laths MX carbonitrides are distributed uniformly [174-176]. Based on the interpretation, the size of the M23C6 particles ranges from 90-230 nm, and the size of the MX carbonitrides varies from 15-60 $\mathrm{nm}$. In the intra-lath region, a high density of free dislocation is visible. The energy dispersive spectroscopy graphs of two different areas with different sizes marked as $A$ and B in Figure 16(b) are given in Figure 16(c) and (d), respectively [177]. Cr and W rich M23C6 carbide are visible in the coarse particle at the $\mathrm{A}$ region because the A region mainly has $\mathrm{Cr}, \mathrm{W}$ and $\mathrm{C}$ elements. Besides, the $\mathrm{B}$ region shows its $\mathrm{V}, \mathrm{Ta}$ and $\mathrm{C}$, $\mathrm{N}$-type carbonitrides due to the chemical composition in this small region are $\mathrm{V}$, Ta. C and N.

The stir zone TEM microstructure of the specimen after welding and after tempering is given in Figure 17. Due to the martensitic transformations in the FSW process, the martensite lath is visible in the stir zone (Figure 17(a)). The results show that while increasing the tempering temperature, the average width of martensitic lath increases exponentially [178]. Figure 17(b) shows that the specimen treated with tempering temperature $720^{\circ} \mathrm{C}$ and the non-tempered specimen has appropriately the same average width of martensitic lath. The dislocation migration due to high-temperature recovery caused dislocation tangles and networks at a tempering temperature of $720^{\circ} \mathrm{C}$. Moreover, fragmented subgrains were formed inside the martensite laths when the tempering

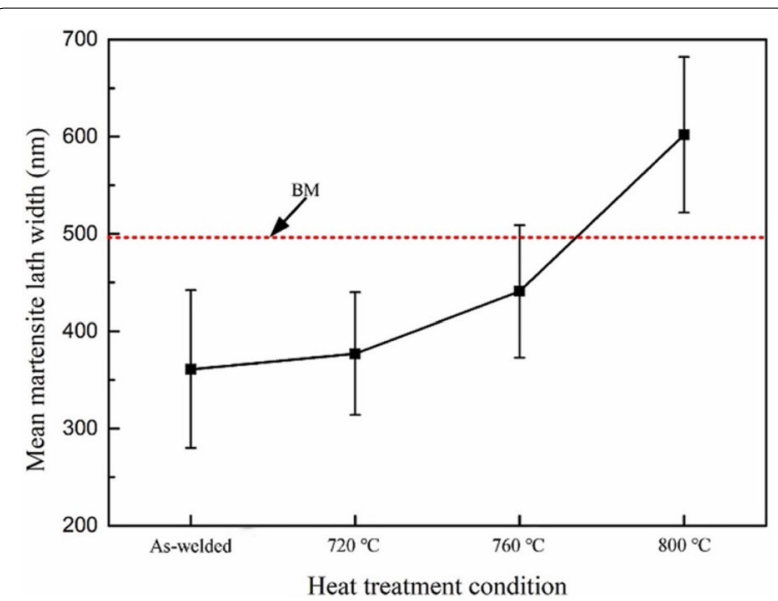

Figure 18 The mean widths of martensite laths or subgrains under different conditions [179]

temperature was increased to $760{ }^{\circ} \mathrm{C}$ (Figure 17(c)). At tempering at $800{ }^{\circ} \mathrm{C}$, it was nearly impossible to identify martensite laths, while an equiaxed grain or subgrains were found (Figure 17(d)).

Figure 18 shows the martensite laths width or the subgrains, determined using the line intercept method. The average width of martensite lath width was $441 \mathrm{~nm}$ when the stir zone was tempered at $760{ }^{\circ} \mathrm{C}$. If the stir zone was tempered at $800{ }^{\circ} \mathrm{C}$, the average width of martensite lath was $602 \mathrm{~nm}$, which exceeds that of the base metal (493 nm) [179].

Figure 19 shows the high magnified transmission electron microscope images of the stir zone, which helps identify the precipitate distribution of the stir zone. Figure 19(a) reveals the dissolved MX carbonitrides dispensed within the martensite lath [180, 181]. The peak temperature attained by the stir zone ranged from 973 ${ }^{\circ} \mathrm{C}$ to $1139^{\circ} \mathrm{C}$. Due to this temperature, M23C6 carbides were hard to find. Thermo-Calc software with the thermodynamic database TCFE9 was used to analyze the equilibrium phases at various temperatures, which helps investigate the evolution of participants. The derived results are given in Figure 20.

In microstructure analysis, the phases like Laves phase and the $\mathrm{Z}$ phase are not visible in the base metal or stir zone of the RAFM steel, so they were omitted from the calculation. Figure 20 shows that below $886{ }^{\circ} \mathrm{C}$, M23C6 carbides were formed. When the temperature was above $988{ }^{\circ} \mathrm{C}$, the MX carbonitrides were dissolved entirely [182], indicating that MX carbonitride withstands higher temperatures than M23C6 carbides. Figure 20 shows the Thermo-Calc calculated data as well. Figure 19(b), (c) and (d) show that the thawed M23C6 and MX phases were reappeared from the supersaturated solid solution of the 

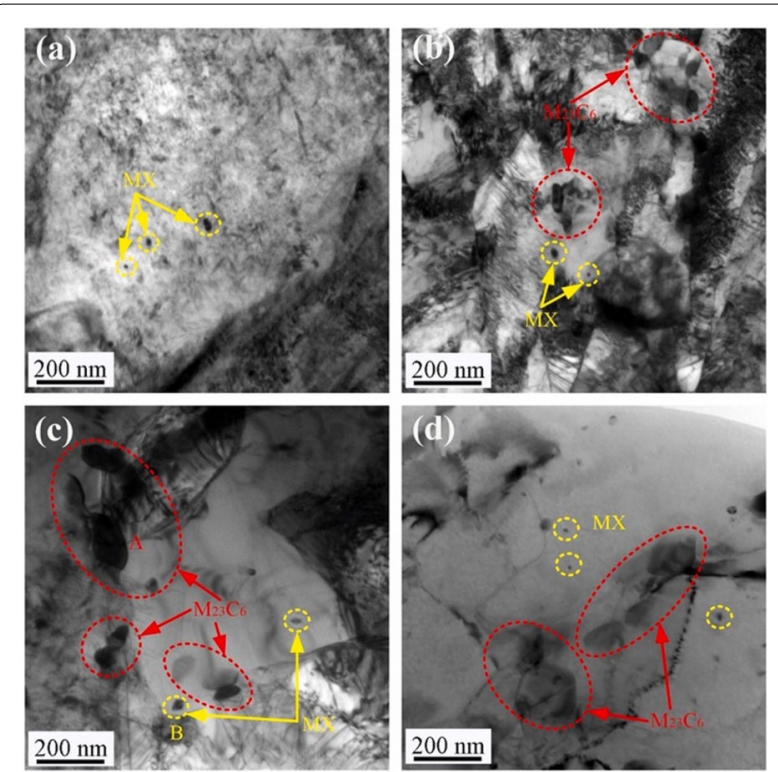

Figure 19 Precipitate distributions of the stir zone (SZ) at different conditions: a SZ in the as-welded, b SZ tempered at $720^{\circ} \mathrm{C}, \mathbf{c}$ SZ tempered at $760^{\circ} \mathrm{C}, \mathbf{d} \mathrm{SZ}$ tempered at $800^{\circ} \mathrm{C}[180]$

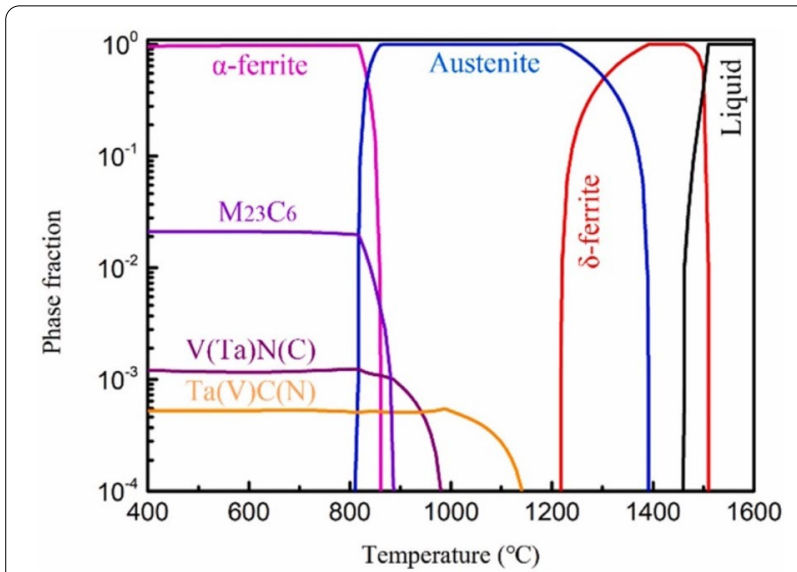

Figure 20 Stability phase in RAFM steel as a function of temperature [180]

martensite matrix after PWTT [183, 184]. In contrast, the friction stir welding of super duplex steel SAF 2507 with a nickel-based superalloy Incoloy 825 indicates that vital microstructure deformation is happened due to the dynamic recrystallization on the dissimilar metal interface, and this will affect the yield strength of the joint.

Multi-material design or multi-material joining have a colossal requirement since joining dissimilar metals with different physical properties and chemical properties can provide a synergic effect like corrosion resistance, high weight reduction, and high impact \& yield strength. These are the results gained from the hybrid uses of such dissimilar metals [185]. With the aid of friction stir welding, steel and aluminium were joined, and this solid-state welding avoids the formation of thick intermetallic compound layers in steel/aluminium joints. The optimized process parameters and a cylindrical tool geometry were the keys for this dissimilar joining process [186]. Three different tools were used for this experiment. For tool-1, shoulder diameter was $25 \mathrm{~mm}$, pin length was $2.85 \mathrm{~mm}$, and pin profile was tapered cylindrical with a 6-8 $\mathrm{mm}$ diameter. For tool-2, shoulder diameter $18 \mathrm{~mm}$, pin length $2.85 \mathrm{~mm}$, tapered cylindrical pin with diameter 5-7 $\mathrm{mm}$. For tool-3, shoulder diameter $13 \mathrm{~mm}$, pin length $2.85 \mathrm{~mm}$, and cylindrical pin profile with diameter $5 \mathrm{~mm}[187,188]$.

The bead geometry and microstructure analysis were carried out using an optical microscope and field emission scanning electron microscope (FESEM) for analyzing the intermetallic compounds (IMC) layer. The phase and composition of the IMC layer were investigated by the XRD method [189]. Figure 21 shows the field emission scanning electron microscope images of the joint interface at higher magnifications.

Figure 21(a) presents the magnified view of the joint interface made by tool-1. It reveals a serrated type of material, which formulae an IMC layer with fragmented particles. In Figure 21(b), the interface of weldment produced by tool- 2 also shows such a damaged IMC layer. A tinny and uninterrupted IMC layer was visible in the weld interface fabricated by tool-3, as shown in Figure 21(c). While exposed to heat, the metallurgically mismatched steel/aluminium joint formed a brittle and hard IMC layer on the close contact region [190]. The joint strength is decreased according to the increase in the composition and thickness of this IMC layer.

The FESEM images also reveal that a unique IMC layer of somewhat different contrast from the parent metal is observable. Also, Figure 21 shows that the IMC layer's thickness varies from $1 \mu \mathrm{m}$ to $4 \mu \mathrm{m}$. This IMC layer variation occurs due to the different diffusion temperatures formed in other regions and the different kinetics of diffusion of materials [191, 192]. For all three joints, the thickness of all the weld interfaces was measured and shown in Figure 21(a1), (b1) and (c1). 10 points were taken for average thickness. The IMC layer thickness gained by tool- 1 is comparatively higher than those formed by the other two tools. The continuous detachment of debris always limits the IMC layer growth. Consequently, for tool- 1 and tool-2, the IMC layer area and the detached fragments nearby get amplified in the stir zone [193, 194]. As evident from Figure 21, the thickness of the IMC layer is about 2.5 $\mu \mathrm{m}$. 

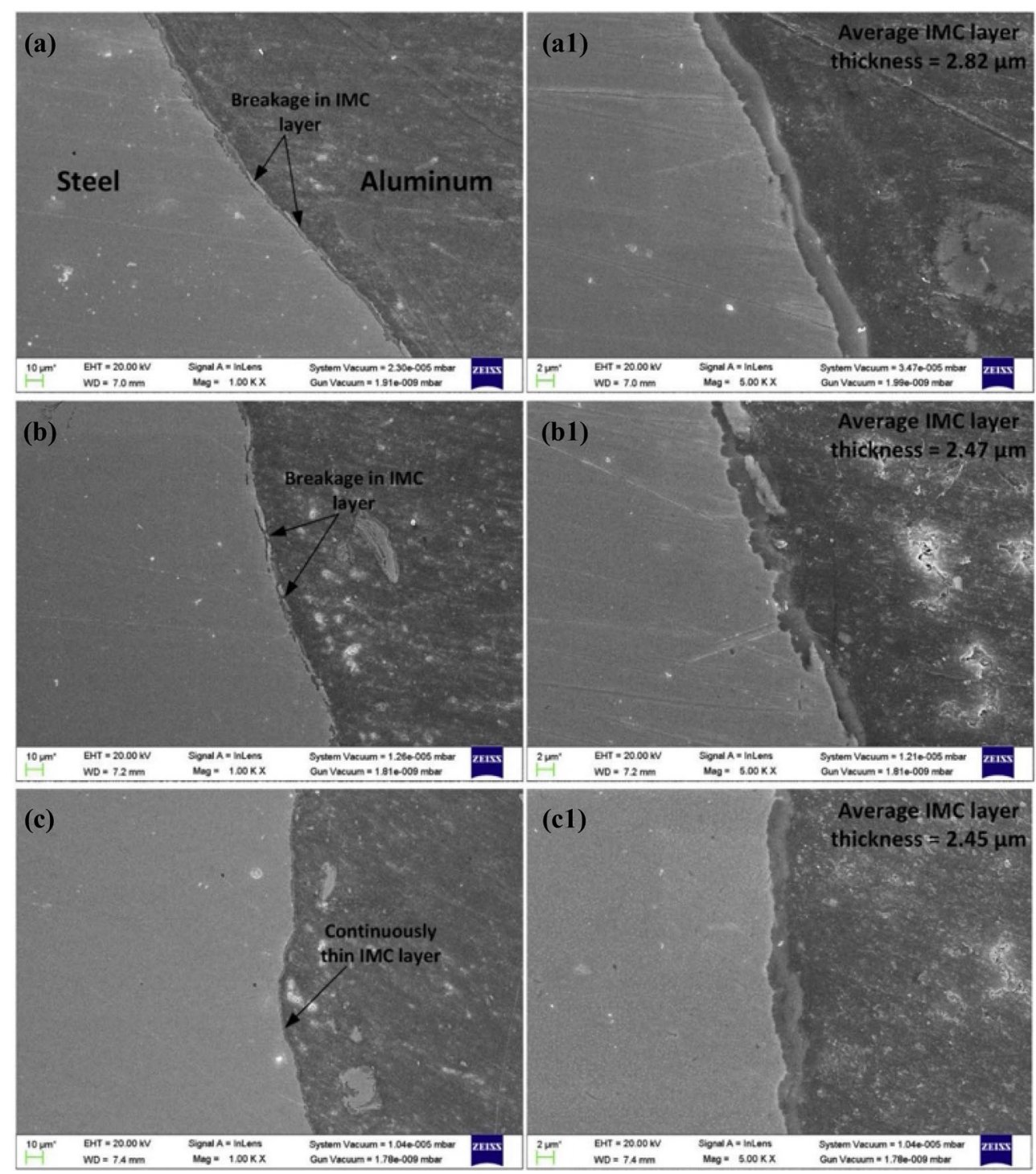

Figure 21 FESEM images of IMC thickness in weld made by a, a1 Tool 1, b, b1 Tool 2, and c, c1 Tool 3 [191]

With the aid of energy-dispersive X-ray spectroscopy (EDS), the chemical line analysis was conducted along the thickest region of the intermetallic layer, as shown in Figure 22(a) and 22(b). This EDS image clearly shows the coexistence of $\mathrm{Al}$ and $\mathrm{Fe}$ in the intermetallic layer in the line analysis curve. To check the existence of various elements, a chemical analysis was initiated for a selected point (Figure 22(c)) [195]. The element analysis method analysed the atomic percentage and weight of different aspects, given in Figure 22(d). The result revealed that the atomic percentage of the aluminium atom was around $73.42 \%$, and the atomic ratio of iron was $25.45 \%$. It is challenging to analyze the intermetallic phases of various composites in this complex system.

Along with the detached steel fragment, elemental analysis was conducted, shown in Figure 22(e) [196]. Reinforced particles were formed in the aluminium matrix due to the congestion of steel fragments in the nugget zone. In Figure 22(f), an IMC layer is visible around the steel debris with a thickness of $5 \mu \mathrm{m}$, thicker than the actual interface of aluminium/steel $[197,198]$. Initially, the detached fragments were part of interfacial steel and an IMC layer formed towards the aluminium side of the exposed surface. While examining the nugget zone, the debris gained a suitable diffusion time due 

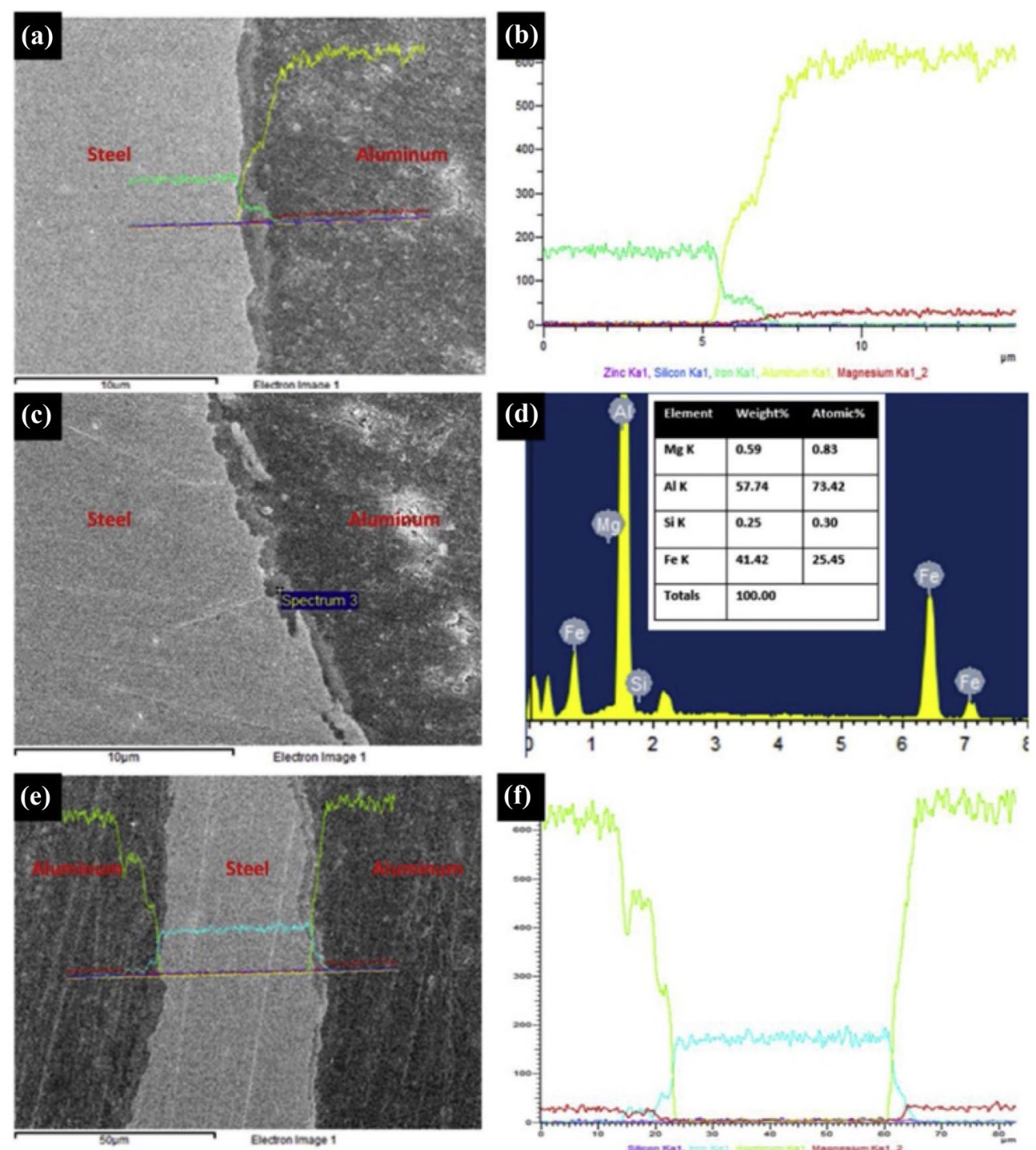

Figure $\mathbf{2 2}$ a, $\mathbf{b}$ Elemental line analysis of interlayer, $\mathbf{c}, \mathbf{d}$ Elemental point scan inside the intermetallic layer and $\mathbf{e}, \mathbf{f}$ Elemental line scan across a detached steel particle [195]

to the higher heat generation, leading to thickening of the IMC layer.

$\mathrm{XRD}$ analysis was conducted for all the fracture tested specimens joined by three tools. The XRD analysis is given in Figure 23.

The XRD analysis showed that the joint fabricated by the tool-1 had the presence of Fe2Al5 beside aluminium and iron. For the tool-2 welded specimen, a more or less similar result was gained. The presence of aluminium metal was visible in the fracture sample made by tool-3. It was evident that the failure in this specimen was due to the aluminium metal and not the IMC layer [199].
With the aid of FESEM, with varying magnifications, the fractured tensile samples were examined, as shown in Figure 24. Figure 24(a) was the joint fabricated by tool-1. For improved clarity, a magnified view was given inside the box [200]. The image portrays that the failure has happened in the down portion of the IMC layer, and a small number of indiscretions were visible in the upper part of the fracture, and the remaining region was almost flat. Due to the high heat generated by the tool plunge depth, an extreme softened aluminium was formed in the upper area of the specimen (Figure 24(a)), which led to the fracture. Some unevenness was visible in the upper area of the fractured specimen prepared by the tool-2, but the 


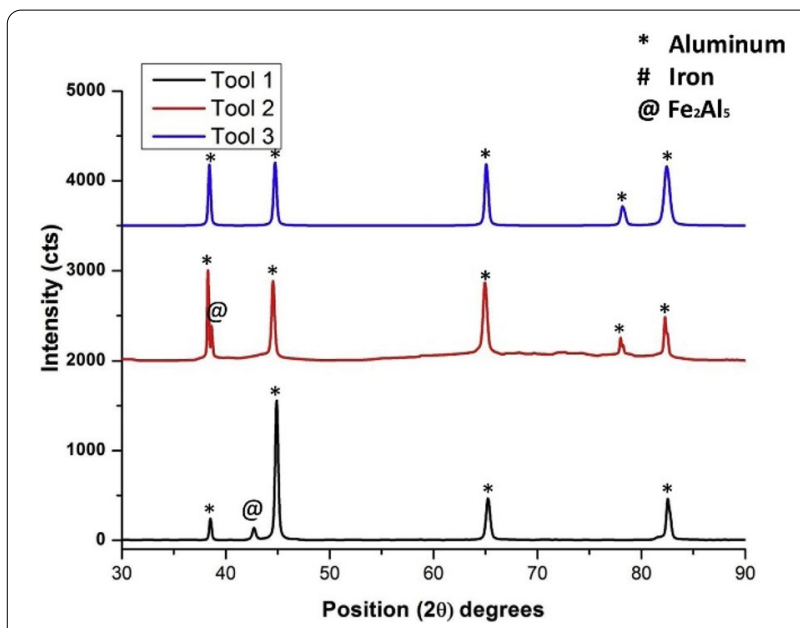

Figure 23 XRD analysis of the fractured surface [199]

bottom area was primarily flat. Figure 24(b) shows the occurrence of dimples in the magnified view, and these dimples caused ductile failure $[201,202]$. Due to the tool spindle speed, the aluminium particles moved upwards along with the tool shoulder over the steel region, leading to the failure of the upper part of the fracture surface, and brittle fracture happened in the bottom.

Nevertheless, the steel and aluminium created an almost flat interface. Figure 24(c) shows the fracture surface of the weldment prepared by tool-3. A ductile failure was visible in the image, and in the magnified view, a web-like arrangement and dimples were visual, which reveals that the failure was happened by the ductile way. Also, some irregular surfaces were visible at the bottom of the specimen, which refers to the interaction of two metals $[203,204]$. The aluminium presence in the fracture surface was visible in the XRD graph of the fracture specimen prepared by tool-3, and steel defragmentation was not due to the proper bonding. The results reveal that a tool causing maximum material movement can provide a better bonding surface and join steel with soft metals like aluminium. The steel grains should be minimized to obtain sound joint strength [205, 206].

Dual-phase (DP) steel 700 was welded successfully by using friction stir welding. The texture development and microstructure formation were examined thoroughly. FESEM analyzed the stir zone microstructure of the DP 700 weldment, as given in Figure 25.

The optical micrograph and the FESEM micrograph of the DP steel stir zone are shown in Figure 25(a) and (b). The image portraits that the stir zone combination of fine martensite, ferrite and retained austenite microstructure. Figure 25(c) and (d) show the stir zone's IPF map and phase map [207]. The grain size in the stir zone had an average length of $1.3 \pm 0.5 \mu \mathrm{m}$, which is comparatively smaller than that in the base metal. Moreover, the $3.8 \%$ of retained austenite dispersed in the ferrite matrix and visible in the phase distribution map (Figure 25(d)). Besides, the austenite's prolonged crystal defect enhanced its constancy against martensitic evolution, resulting in an improved level of retained austenite in the microstructure [208, 209]. Nevertheless, the martensite and ferrite have a BCC structure, so it is hard to identify duplex steels. However, in the IFP map, this phase is seen as a cluster of comparatively arbitrarily oriented points.

Furthermore, the Kernal average Misorientation (KAM) maps were also interpreted to examine the validity and accuracy of the threshold. Significant differences are detected in the intermediate level of distortions in different grains, a grain distinct related to the minor boundaries of 50 , and the most petite pixels of 4 is significant [210].

Based on the above Kernal average Misorientation map approach, the separation of martensite and ferrite is given in figure 26 . The volume fraction was estimated to be $11.3 \%$ and $84.9 \%$ for martensite and ferrite, respectively. This volume fraction was calculated from many SEM images analyses [211]. The martensite and austenite elements were eliminated, and the IPF map of the ferrite phase was plotted in Figure 26(d). Figure 26(e)-(f) show the grain boundaries map and misorientation angle distribution. It is visible that primarily all the HABs established closed structures, and equiaxed ferrite grains were also visible [212-214]. The yellow arrow in Figure 26(e) represents the structure free of LABs, which symbolize that recrystallization had been finished. During the dynamic recovery process, steady accumulation and reordering of grains dislocations led to the formation of grains having LABs. The green arrows and red arrows in Figure 26(e) represent the adequate extent of dynamic recovery and inadequate dynamic recovery during the process, respectively [215]. Figure 26(f) illustrates that most of the LABs vary from 20 to 50 . The research found that the recovery mechanism for the ferrite phase in the stir zone was continuous dynamic recrystallization and discontinuous dynamic recrystallization. Due to the lower strain in the thermomechanically affected zone, geometric dynamic crystallization was also involved in the ferritic phase recovery [216]. The primary recovery mechanism for ferrite in the thermomechanically affected zone and stir zone were continuous dynamic recrystallization.

Friction stir welding on $12 \mathrm{Cr}$ oxide dispersion strengthened (ODS) steel was successfully executed. The results have shown that the grain size in the stir zone was smaller than the base metal. The dynamic recrystallization in the stir zone and the thermomechanically affected zone was 

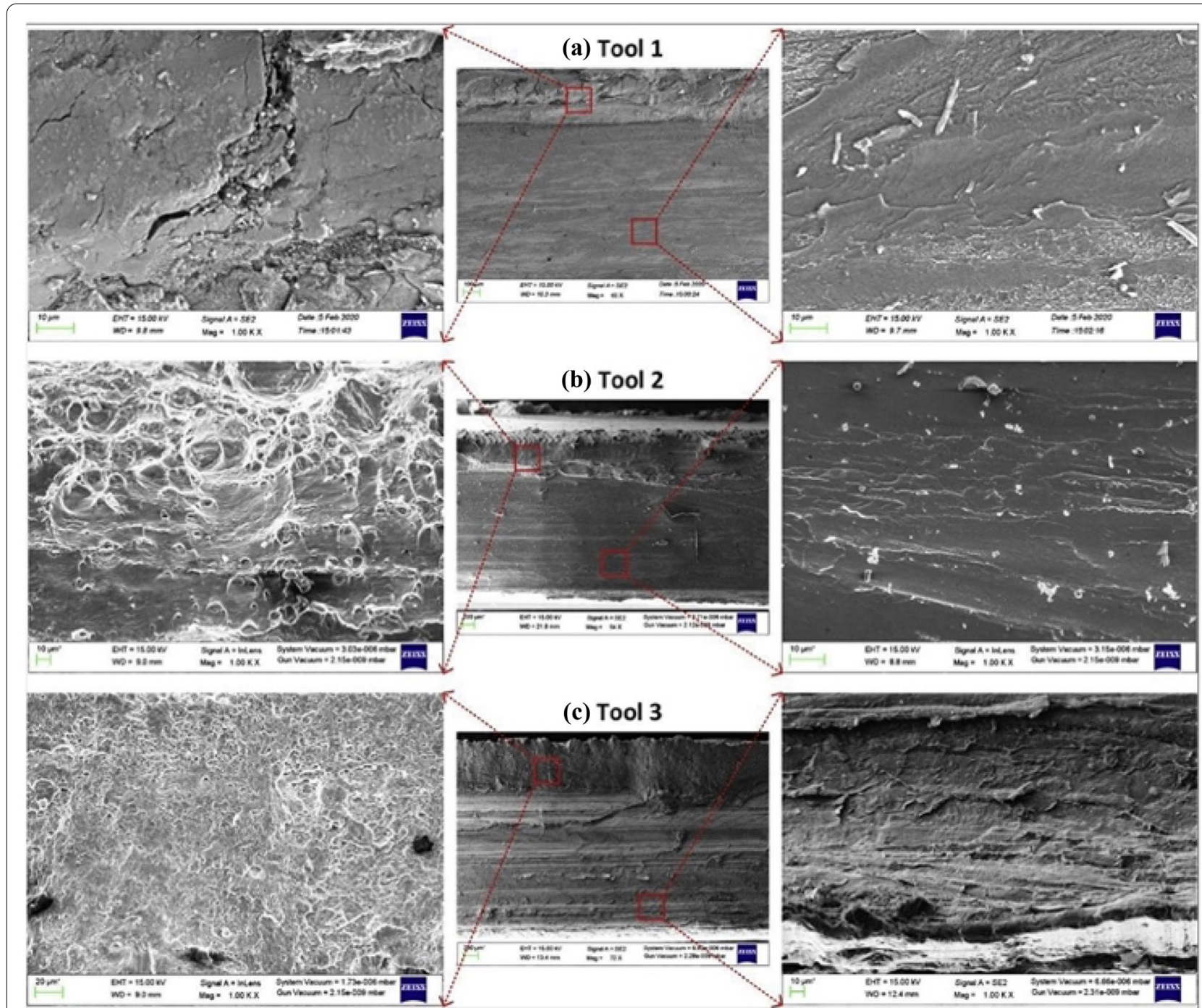

Figure 24 FESEM images of fractured surface in tensile loading of welds made by $\mathbf{a}$ Tool 1, b Tool 2, and $\mathbf{c}$ Tool 3 [200]

analyzed by electron backscattering diffraction (EBSD) results. It was observed that a changeover from low angle boundaries (LAB) to high angle boundaries (HAB) was convoyed by the dynamic recrystallization process [217].

The 12Cr-OSD steel weldments IPF maps were taken from different areas of the joint, as shown in Figure 27. The different colours and patterns in Figure 27(f) represent different crystallographic orientations.

The average grain size of the various zones was measured by the intercept method, and Figure 28 portraits the histogram of grain size distribution. Figure 28(a) shows the number fraction of grain size in the base metal. The grain size in base metal was $1249 \mathrm{~nm}$, where the grain size in the heat-affected zone was $1121 \mathrm{~nm}$, which was comparatively smaller than the base metal (Figure 28(b)); this is due to the recrystallization that happened in the metal due to heat generated by FSW process [218-220]. The grain structure found in the stir zone was vastly different from the base metal and HAZ. The grain size in the stir zone was $358 \mathrm{~nm}$, and the refined grains were uniformly distributed due to the dynamic recrystallization in the stir zone, as shown in Figure 28(c). The breakage of grains in the stir zone resulted in a refined grain structure. The heat-affected zone and thermomechanical affected zone grains did not break much and resulted in $878 \mathrm{~nm}$ and $1245 \mathrm{~nm}$, respectively [221, 222].

Figure 29 shows the 12Cr-ODS steel joint's EBSD grain boundary misorientation angle distribution in base metal, stir zone and thermomechanical affected zone. The blue line showed the misorientation angle 

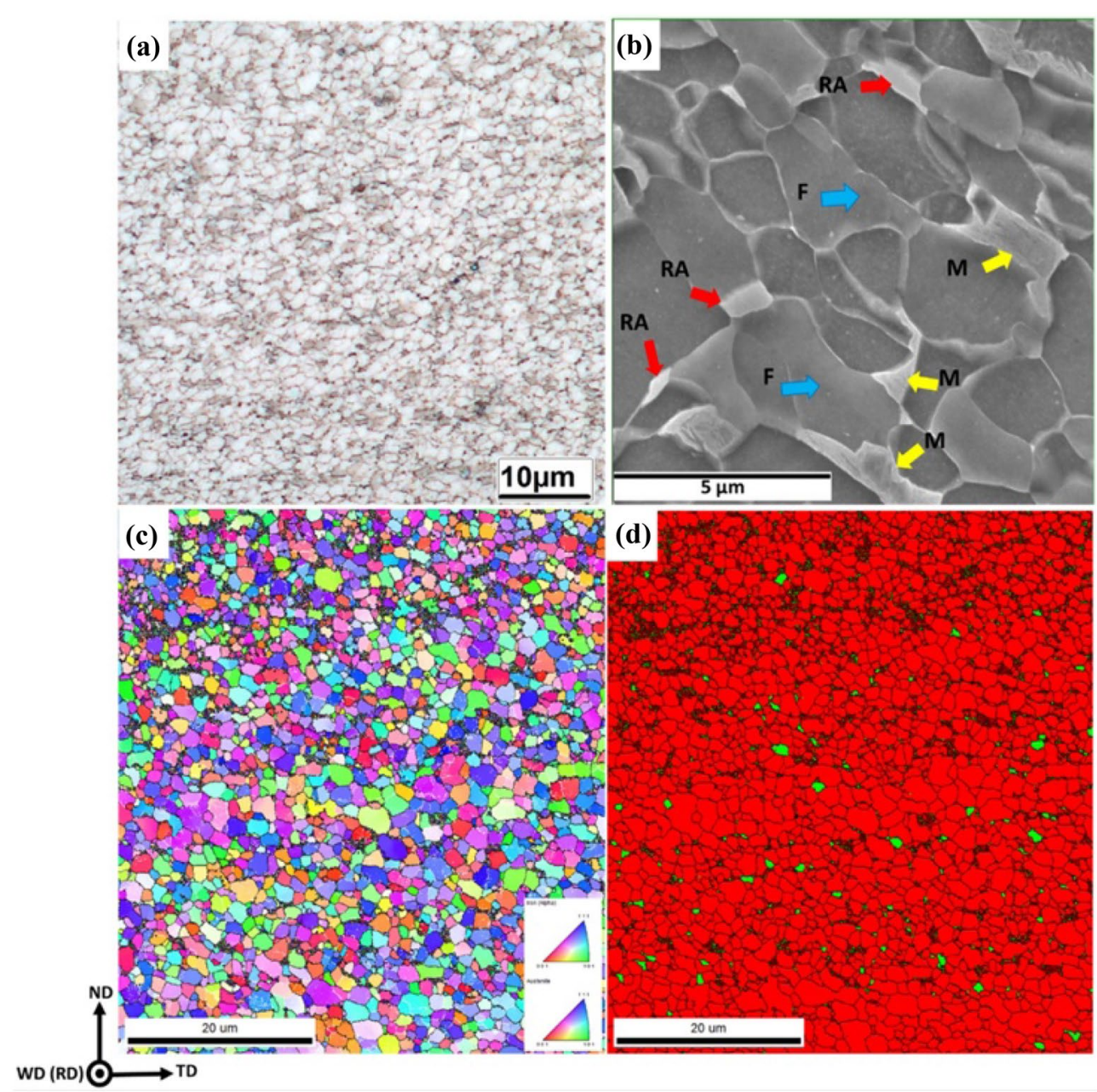

Figure 25 Microstructure of the centre of the SZ: a Optical image, b FESEM image, c IPF map, d Corresponding phase distribution map [207]

of more than 150, i.e., the high angle boundary. The misorientation angle less than 150, i.e., the low angle boundary (50 to 150), was portraited in green, and the red line showed those with misorientation angle20 to 50. Figure 29(a) shows that the fraction of LABs was around $49.9 \%$ and the elongated grains enclosed by the vast number of HABs. HAB formation increased to $86 \%$, the metal flow and mechanical force highly promoted the recrystallization in the stir zone [223, 224]. Figure 29(b) shows that the grain boundaries of the stir zone were more refined, and the grain was distributed evenly compared to the base metal. Equiaxed grains and the $L A B$ distributed besides the flow track were noticeable in the TMAZ region due to the recrystallization process, as shown in Figure 29(c). The researchers concluded that $49.4 \%, 85.6 \%$ and $49.6 \%$ were the recrystallization percentages in the heat-affected zone, stir zone and thermomechanical affected zone, respectively [225].

\section{Process Variants in FSW of Steels}

Implementing FSW for high melting point metals like steel is quite challenging due to the tool wear. The replacement of tools in a short span of welding makes the process costly. One of the best methods to attain a prolonged tool life is to adopt preheating or in-situ heating techniques to soften the weld region before the tool enters. This softening of the weld region will reduce the wear rate of the tool, and therefore the tool life will increase. This method is called Hybrid Friction Stir Welding.

Hybrid FSW means an additional heating source is attached with the conventional FSW process for preheating or in-situ heating the metal plates before the tool plunging [226-228]. This method helps to plasticize the tool plunging area of the metals, and through this, the plunging and tool movement will be much easier. Figure 30 shows the schematic diagram for a hybrid FSW process. 


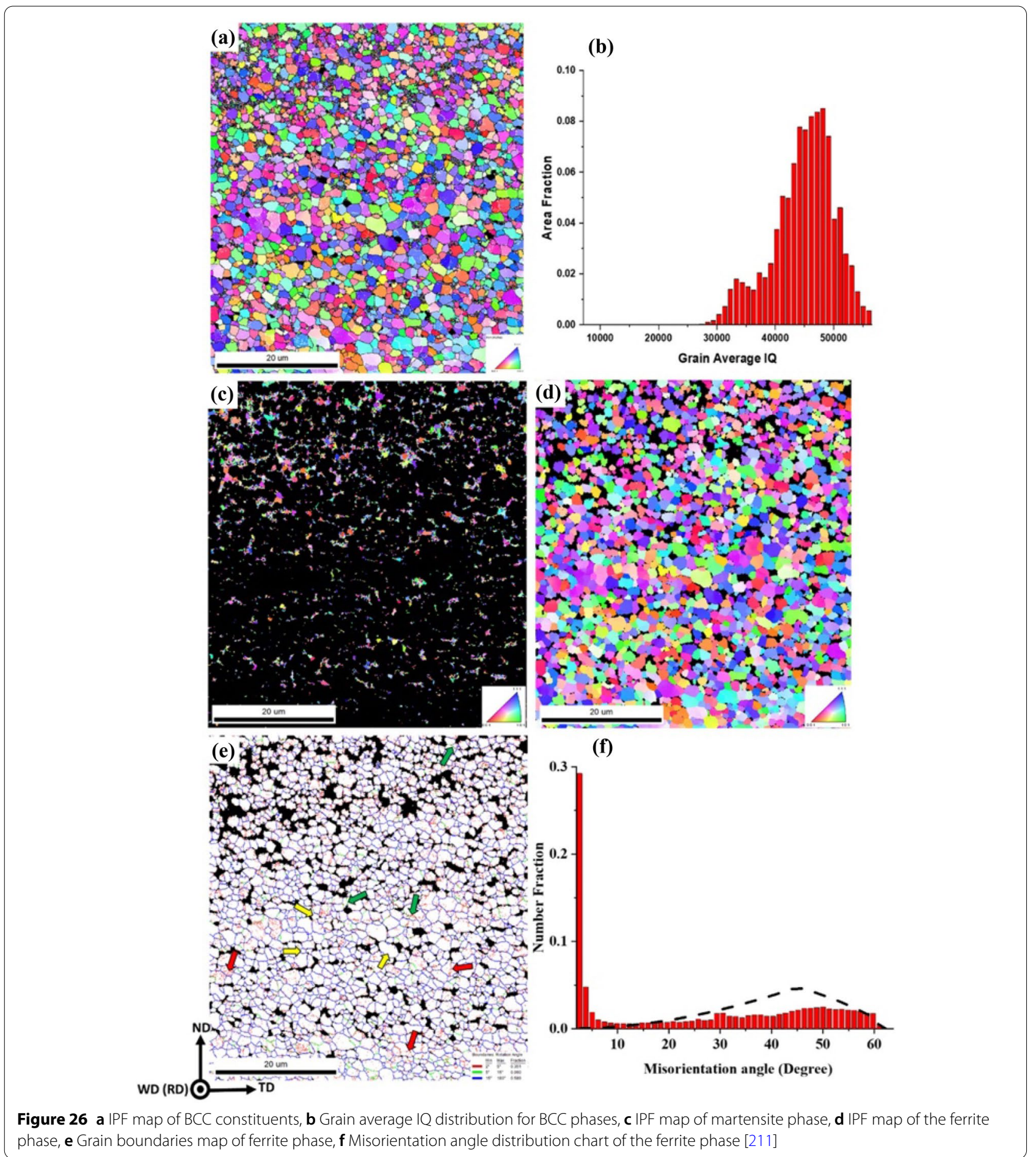

This method helps to reduce the tool damages due to high axial force while plunging. Through this method, FSW of steels can take over by using HSS or tungsten carbide tools. The welding cost will be much cheaper through this technique than the PCBN tool used in the
FSW process [229]. The widely used preheating or in-situ heating techniques are laser heating, ultrasonic vibration and induction heating. Laser heating can be applicable for magnetic and non-magnetic alloys, while induction is more capable in ferromagnetic steels [230-232]. 

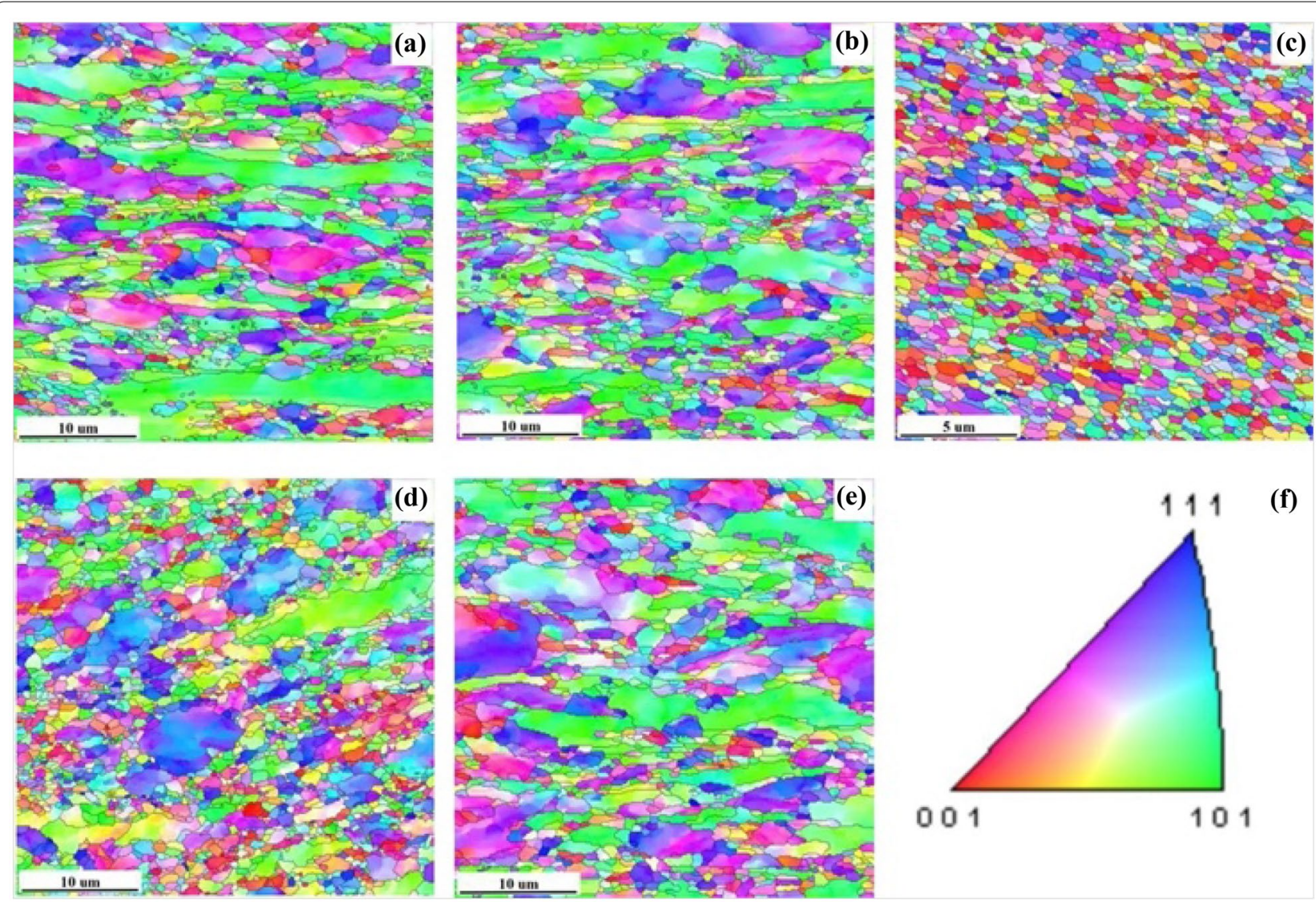

(f)

Figure 27 EBSD IPF maps of a BM, b HAZ, c SZ, d AS-TMAZ, e RS-TMAZ, and f Orientation [217]

\subsection{Laser-assisted FSW}

In laser-assisted friction stir welding (LAFSW), the dominating process is friction stir welding, and the supporting process is laser heating. The supportive process helps preheat or in-situ heat the weld region of the metal plates before the tool approaches [233]. The laser beam produces localized heating in the weld zone and makes the region get plasticized, and this helps the tool move quickly through the metal. Due to the enhanced plastic deformation of the metal, the tool damage or tool wear is reduced, and high welding speed is attained [234].

Figure 31 shows the laser-assisted friction stir welding setup. A cold rolled DC04 steel was welded by using the LAFSW method. A $2 \mathrm{~kW}$ laser was adopted. It demonstrated that the laser beam lowered the residual stress and enhanced the weld zone's microhardness. The nugget shape was transformed drastically, but it did not change the metal's microstructure [235]. The in-situ heating helps to attain a higher elongation without changing the mechanical strength. Besides, the microhardness improved in the in-situ heated region, and the tool wear was reduced drastically and achieved a better welding speed.
LAFSW method can be used to join dissimilar metals like steel and aluminium [236]. While examining the grain structure in these dissimilar metals joining, the grain size gained is different in different areas. The bigger-sized grains were visible in the heat-affected zone, the medium size was viewable in the thermomechanical affected zones, and the refined grains were found in the nugget zones. The main reason for achieving such a different grain structure is the different cooling rates of dissimilar metals. Figure 32 shows the schematic representation of grain structure in the steel/aluminium friction stir welded joints.

\subsection{Induction Heat-Assisted FSW}

Comparing with laser-assisted FSW, the induction heatassisted friction stir welding (IA-FSW) have some advantages. It is quite challenging to operate a laser on a glossy metal surface or mirror finish metal surfaces due to the reflection property of the laser. When it comes to ferromagnetic materials, induction heat is economical. Induction heating can heat the parent metals locally in a much faster way. The setup and installation of the induction heater are effortless, and they can be handled easily. The 

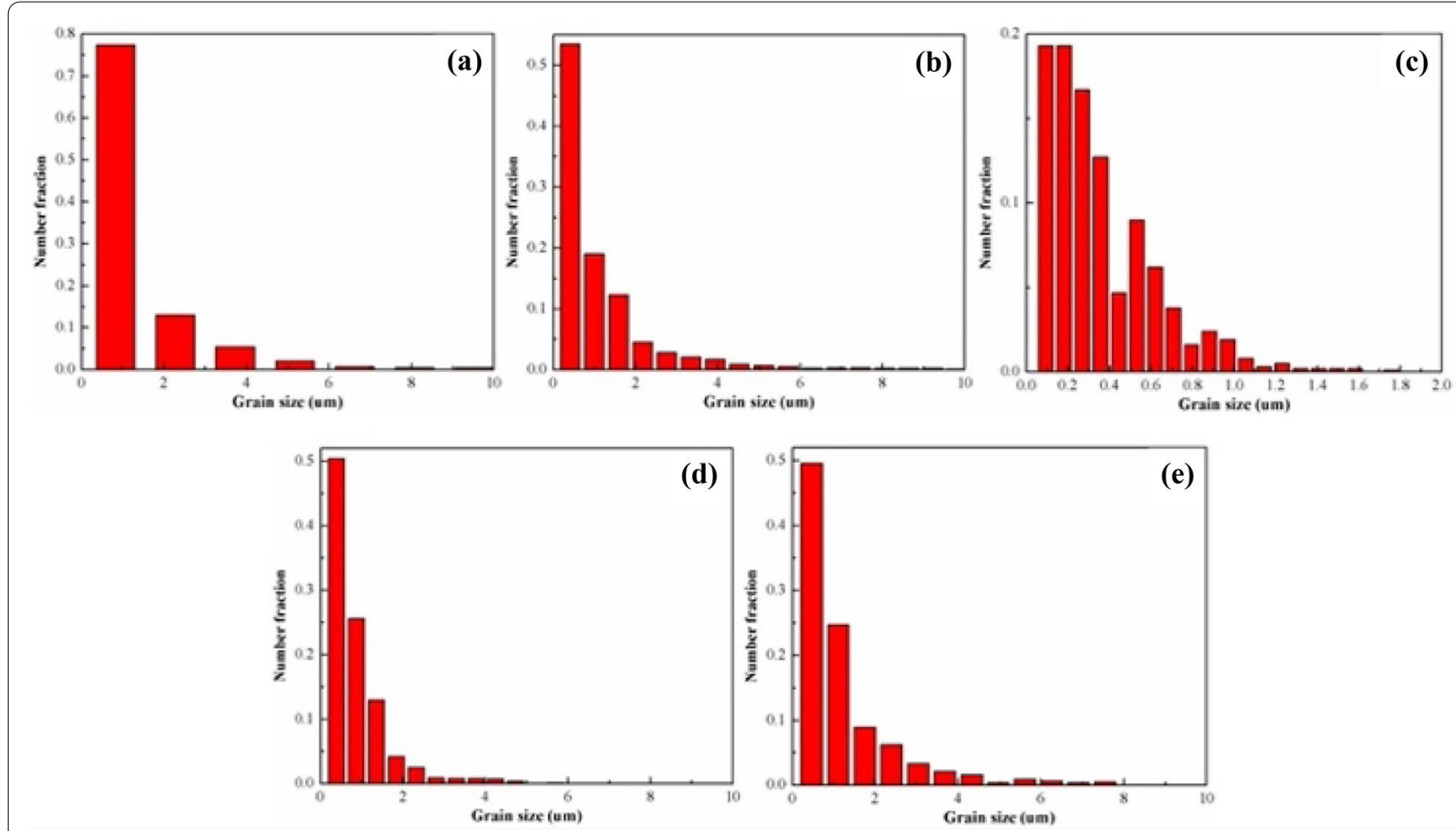

Figure $\mathbf{2 8}$ Grain size distributions of $\mathbf{a} B M, \mathbf{b} H A Z, \mathbf{c} S Z$, $\mathbf{d} A S-T M A Z$, and e RS-TMAZ [218]
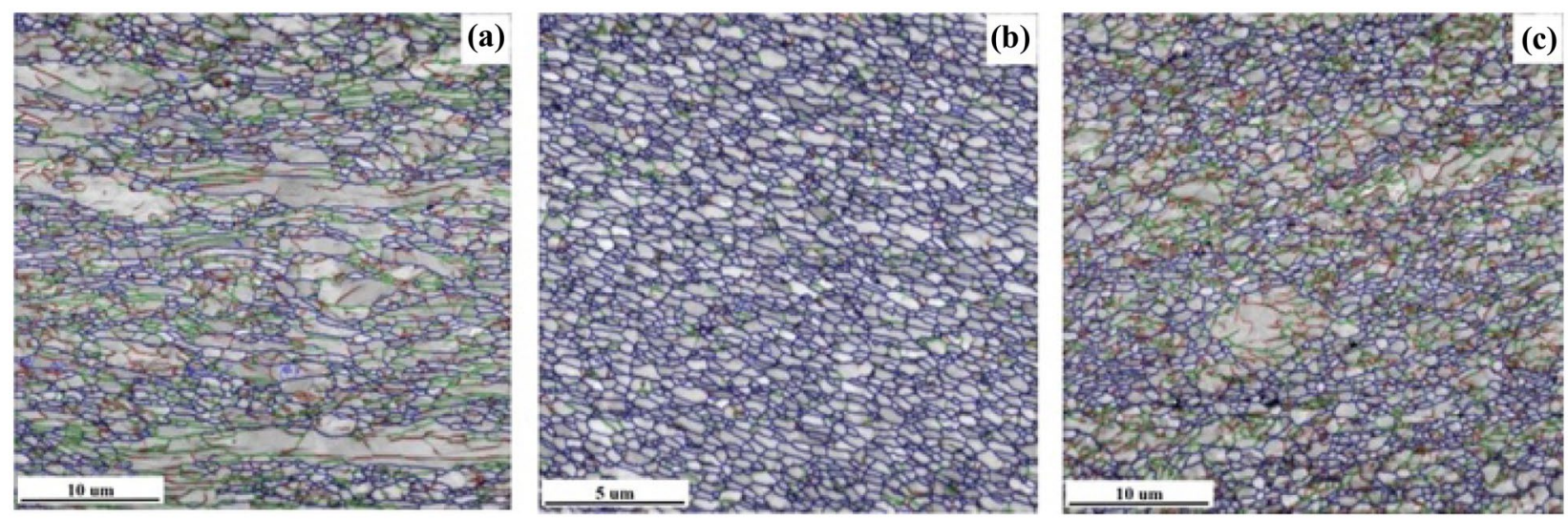

Figure 29 EBSD grain boundary misorientation angle distributions: a Base metal, b Stir zone, c Thermomechanical affected zone [223]

power wattage adjustment attains the required temperature. Figure 33 shows the IA-FSW setup [237, 238].

An AISI 410 stainless steel was successfully welded by using IA-FSW. The results indicated that the microstructure formed in the nugget zone was much more refined than the base metal due to dynamic recrystallization. Similarly, this in-situ heating and dynamic recrystallization helped improve the microhardness of the stir zone. The corrosion studies conducted by (three and twenty-four hours) weight-loss method with the aid of $0.5 \mathrm{M} \mathrm{H} 2 \mathrm{SO} 4$ showed that the stir zone improved corrosion resistance property due to refined grain formation [239]. The in-situ heating increased the welding speed, lowered clamping force, and reduced tool wear.

The induction assisted friction stir welded AISI 410 stainless steel shows that the tool's travelling speed is much higher than conventional FSW [240-243]. The microstructure revealed that a fine homogeneous 

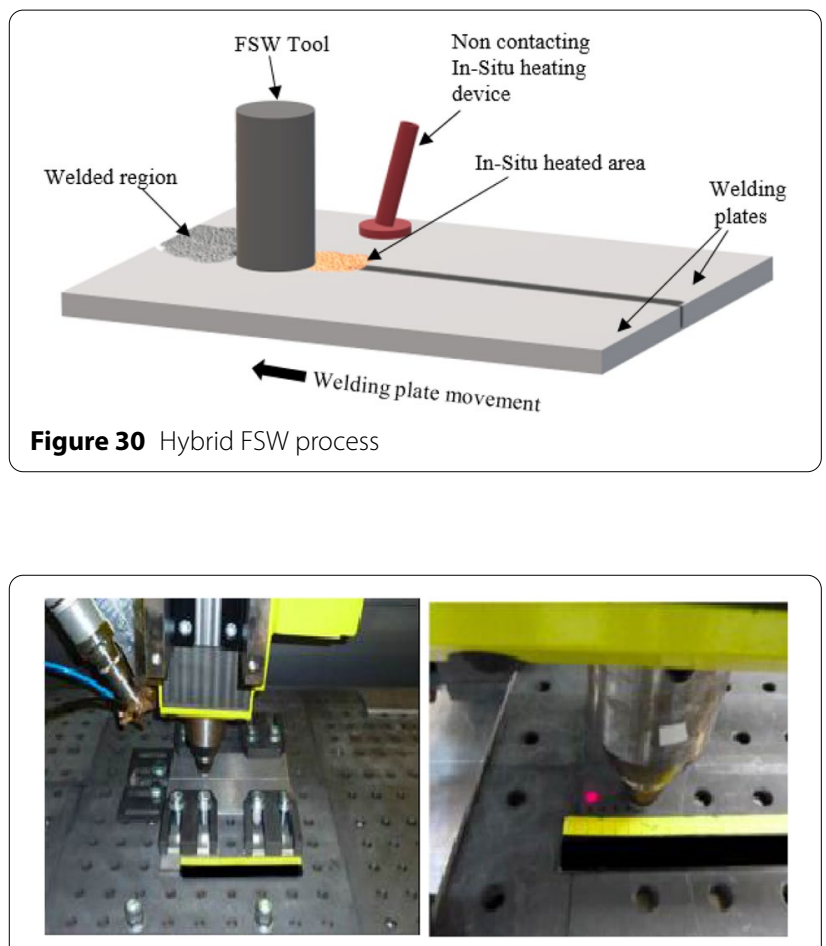

Figure 31 Laser-assisted friction stir welding [235]

\subsection{Gas Tungsten Arc Welding Assisted FSW}

AZ31B magnesium alloy and SS400 mild steel were successfully joined using gas tungsten arc-friction stir welding [244]. In this joining process, the preheating focuses on the SS400 mild steel because magnesium alloy has a lesser melting point than mild steel. Comparing standard friction stir welded joints and gas tungsten arc assisted friction stir welded (GTA-FSWW) joints was done. The results show that the GTA-FSW joints have superior strength than the usual friction stir welded joints. The tensile strength gained was $91 \%$ of the strength of magnesium alloy AZ31B, that is $237 \mathrm{MPa}$, which is higher than the strength gained by conventional friction stir welding, which is $226 \mathrm{MPa}$, which is the $77 \%$ strength of the AZ31B magnesium alloy [245, 246]. The enhanced plastic flow enhances the tensile strength, and the limited annealing happened on the AZ31B magnesium alloy by the in-situ heating of GTA-FSW. Moreover, the maximum welding speed achieved by the GTA-FSW is 72 $\mathrm{mm} / \mathrm{min}$, while the counterpart conventional friction stir welding achieved only $55 \mathrm{~mm} / \mathrm{min}$ welding speed. Figure 34 shows the optical microscope images of the distinct regions of friction stir welded and GTA-FS welded joints.

A fine equiaxed grain structure is visible in the microstructure of the base metal (A) in the magnesium alloy,

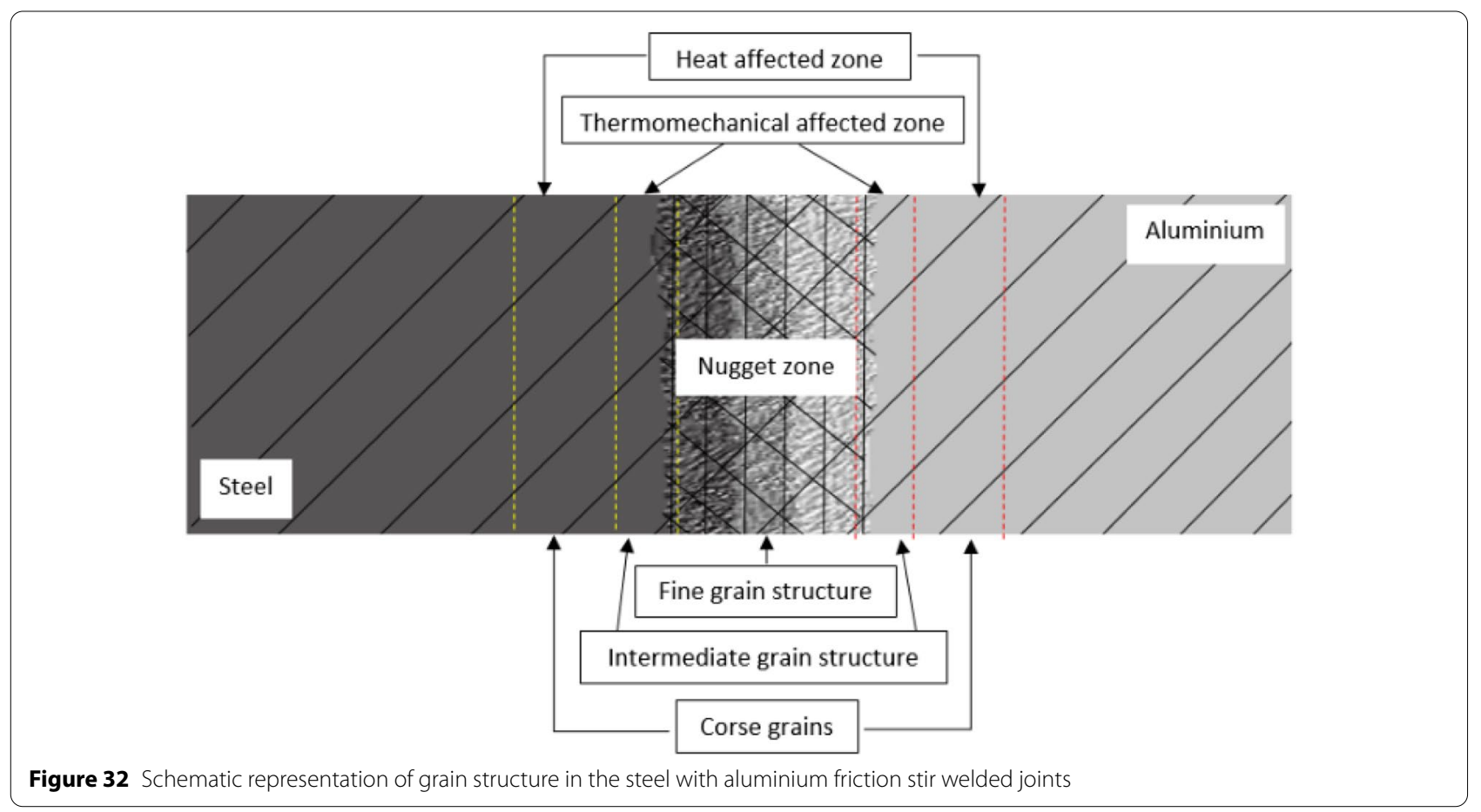

martensitic grain structure was found in the stir zone. The formation of an exemplary microstructure enhanced joint strength of $467 \mathrm{MPa}$. as shown in Figure 34(a). The heat-affected zone and the thermomechanical affected zone in the magnesium alloy 

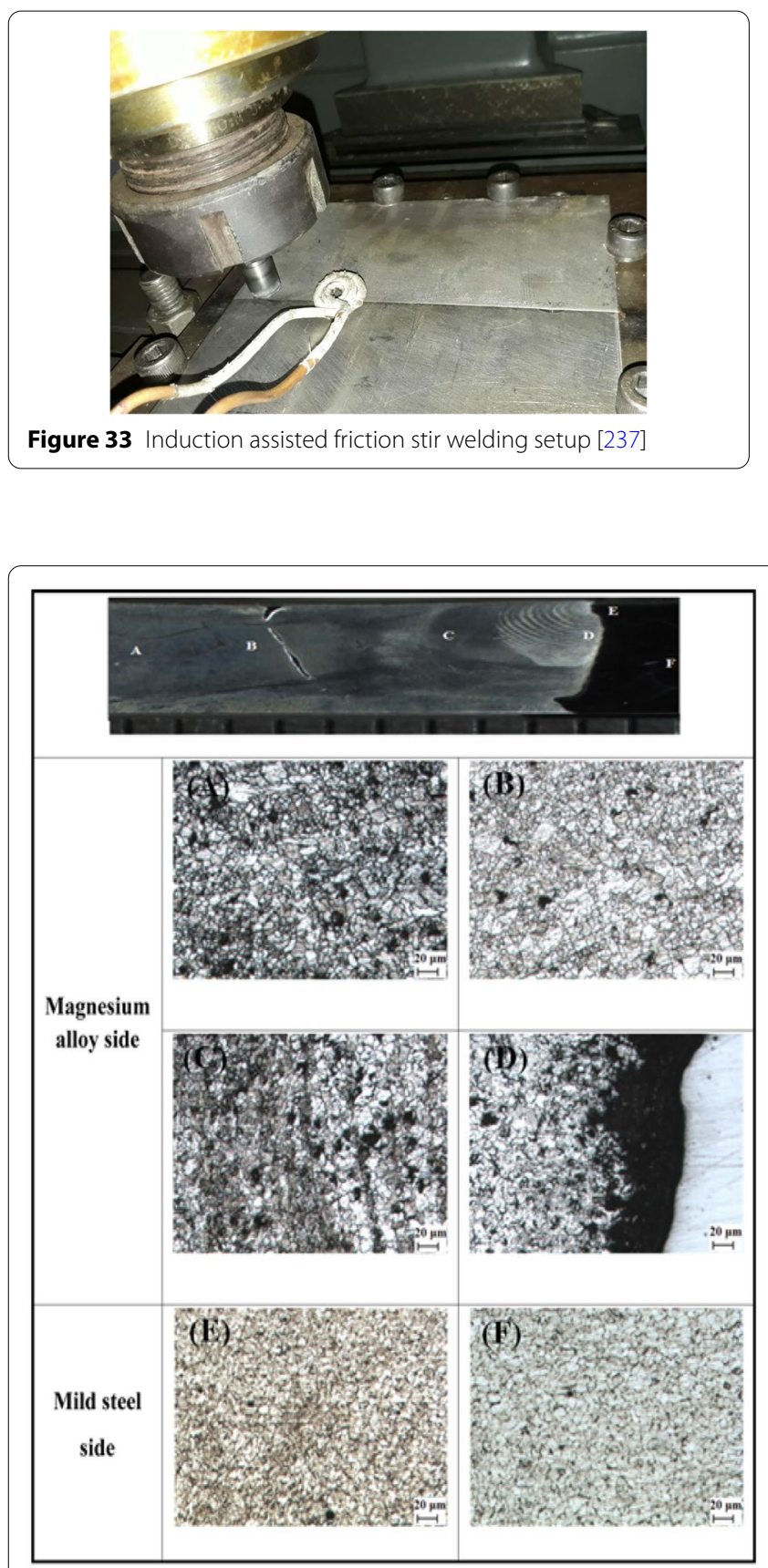

(a) the mechanical stirring and the frictional heat generated by the tool. Similarly, a refined grain structure is found in the stir zone $(\mathrm{C})$ due to plastic deformation, and the weld nugget (D) shows a bimetal interface of magnesium alloy and mild steel. The bottom region provides a nonmixed structure [247]. While examining the lower and upper area of the nugget zone of mild steel (E) exhibits uniform size and shape. Moreover, the microstructure in the TMAZ and HAZ of the mild steel (F) shows a more or less similar grain structure to the base metal.

Figure 34(b) shows the microstructure of GTA-FSW joints. Due to the in-situ heating, the average grain size of magnesium alloys become $16.4 \mu \mathrm{m}$ and which is slightly coarser than the FSW joint (B). The stir zone (C) shows

Figure 34 Optical microstructure of the distinct regions of the weldments a shows the microstructure of the FSW and $\mathbf{b}$ shows the microstructure of the GTA-FSW [245]

(B) also exhibits a comparatively similar grain structure. The grain size in the HAZ is $12.4 \mu \mathrm{m}$, where the grain size in the base metal is around $8.2 \mu \mathrm{m}$, which means the HAZ has a slightly coarser grain structure. While in the TMAZ region (B), the size of the grains found was $7.1 \mu \mathrm{m}$, which is an almost fine grain structure due to

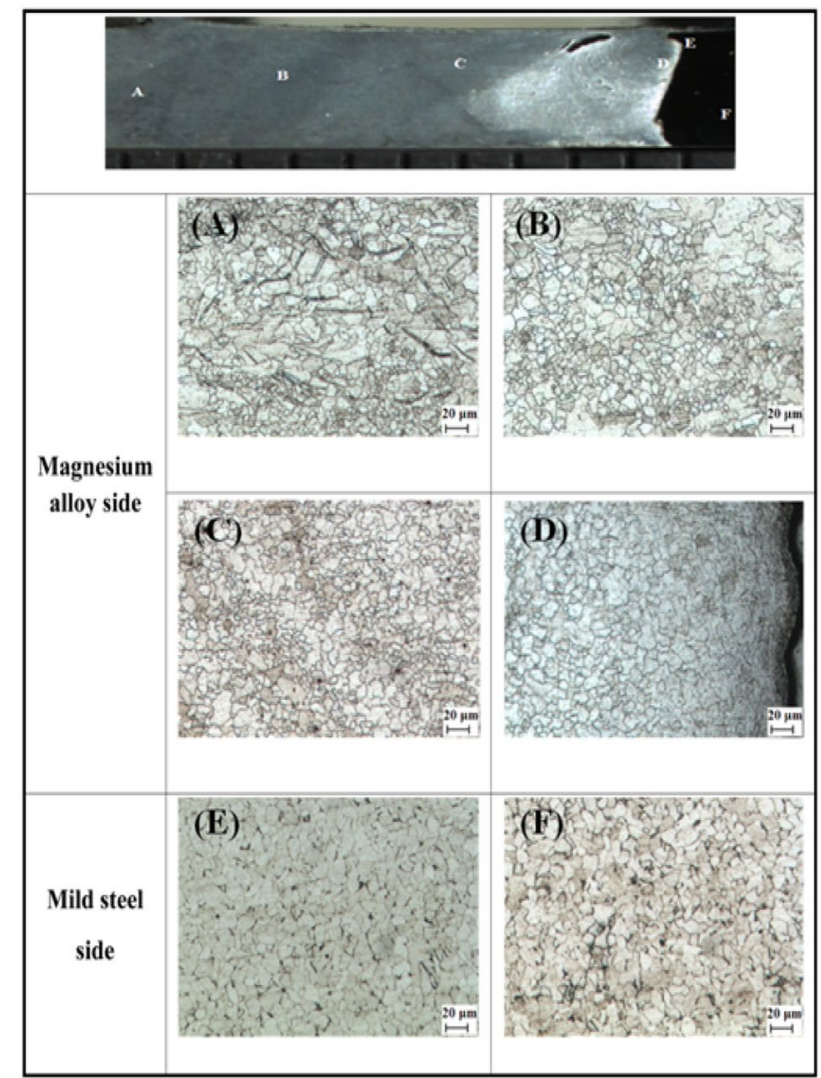

(b) 
the upper portion has a fine grain structure (E) due to the work hardening that happened due to the tool stirring and the in-situ heating by GTAW during joining. In contrast, the grain structure in the HAZ and TMAZ in the mild steel region (F) was slightly coarser than FSW joints due to the in-situ heat input. In contrast, this research shows that a good joint with better strength can be achieved by using GTA-FSW joining method.

\section{Summary and Future Work}

Friction stir welding of steels reached a certain height recently. Many types of research have been conducted to find better combinations like tool material, tool profile, welding speed, tool rotation speed, axial force, and tool tilt angles. This research shows that better steel joints can be fabricated by using friction stir welding [248]. While considering the structure changes, the primary factor affecting heat generation is welding and cooling rate. A fine-grain structure can be achieved in the weld region by controlling the heat generation and cooling rate after welding [249]. This method will enhance the tensile as well as the toughness of the joints. While comparing with the conventional fusion welding techniques, this friction stir welding has many advantages. The pollution that occurs while friction stir welding is nearly nil; porosity and hydrogen embrittlement should not happen while using FSW. Moreover, the heat-affected zone is comparatively less, and the mechanical and corrosive properties of the joints are far better than fusion-welded joints [250]. The paramount aim of this research is to identify the benefits and limitations of FSW while applying the same method to join different grades of steel.

Comparing with fusion welding methods, this FSW method has many advantages like higher mechanical properties, corrosion resistance property, lesser heataffected zone, and FSW does not require any filler metals or special environments to join steel [251]. FSW showed a substantial saving in power consumption. The power consumed in fusion welding was four times or higher than FSW for fabricating similar joints. Also, FSW exhibits better microhardness in the weld zone compared to fusion welding. Moreover, the HAZ in FSW was narrower than that in fusion welding. Nevertheless, the fusion welding process produces higher amounts of harmful gases such as carbon monoxide and carbon dioxide to the surroundings ( $2.7 \mathrm{ppm}$ and $346 \mathrm{ppm}$, respectively). At the same time, the FSW is a green method, which does not produce any harmful gases. [252, 253].

The review on the friction stir welding on steel shows that more research is needed to conduct similar and dissimilar steels and other alloys using hybrid and conventional FSW to reduce the joining costs and enrich the commercialization of friction stir welding in all-metal joining areas. The above review shows that most researchers concentrate on enhancing the strength of the joints, and a few are concentrated on the economic feasibility of the research. Numerous researches were conducted on similar stainless steel joints using PCBN like expensive tools; still, the strength gained was inadequate [254]. Using such tools are not recommendable due to its high expense. In dissimilar metal joining, the microstructure generated in the bimetal region is satisfactory, and the strength gained is insufficient to adopt this method to industry [255]. While laser-assisted FSW and induction heated FSW is widely used for welding steel and its alloys. One of the limitations of IA-FSW is that it can only use for ferromagnetic materials, while ultrasonic vibration-assisted friction stir welding can be adopted for any metals. High strength metals require high heat input to increase the metal flow to obtain a good joint. This volumetric material flow can be enhanced by clubbing an ultrasonic vibration unit with the friction stir welding unit. The significant advantage of ultrasonic vibrationassisted friction stir welding (UVAFSW) is that this ultrasonic vibration is directly given to the tool itself, so there is no energy loss. But since no evident research is undertaken on ultrasonic vibration-assisted FSW for steel and its alloys, this research area requires more attention.

While considering metal matrix composites (MMC), these MMC's are poorly explored using friction stir welding. Dissimilar MMC joining by friction stir welding is still in the nascent stage. These limitations can be addressed by using hybrid friction stir welding and advance FSW tools. Still, enough researches are conducted on the cryogenic post-weld treatments for friction stir weld specimens. The study on pre and post-weld treatments' effect on steels is a prerequisite in friction stir welding research. The impact of different profiled bobbin tools on steel friction stir welding needs more studies. These are the current research voids found in the friction stir welding of steels, which are required to address well.

\section{Acknowledgements \\ One of the authors (DM) would like to acknowledge the Postdoctoral Fellow- ship of Shandong University, China.}

\section{Authors' Contributions}

DM conducted data analysis and wrote the draft manuscript; CW proposed the outlines and modified the manuscript. All authors read and approved the final manuscript.

\section{Authors' Information}

Dhanesh G Mohan, born in 1986, is currently a postdoctoral research fellow at Institute of Materials Joining, Shandong University, China. He received his master degree from Government College of Technology, Coimbatore, Tamilnadu, India, in 2014 and received his PhD from Anna University, Chennai, Tamilnadu, India, in 2019. His research interests include friction stir welding, corrosion engineering and additive manufacturing. E-mail: dhaneshgm@gmail.com.

Chuansong Wu, born in 1959, is currently a professor at Institute of Materials Joining, Shandong University, China. He received his BS, MS and PhD degrees in Harbin Institute of Technology, China, in 1982, 1984 and 1988, respectively. He 
is Fellow of American Welding Society. His research interests include welding physics, friction stir welding and high-efficient arc welding processes. E-mail: wucs@sdu.edu.cn.

\section{Funding}

Supported by National Natural Science Foundation of China (Grant No.

51842507).

\section{Competing Interests}

The authors declare no competing financial interests.

Received: 22 June 2021 Revised: 4 October 2021 Accepted: 14 November 2021

Published online: 14 December 2021

\section{References}

[1] Y S Sato, H Kokawa, H T Fujii, et al. Mechanical properties and microstructure of dissimilar friction stir welds of $11 \mathrm{Cr}$-Ferritic/Martensitic steel to 316 stainless steel. Metallurgical and Materials Transactions A:Physical Metallurgy and Materials Science, 2015, 46(12): 5789-5800.

[2] M Hajian, A Abdollah-zadeh, S S Rezaei-Nejad, et al. Microstructure and mechanical properties of friction stir processed AISI 316L stainless steel. Materials and Design, 2015, 67: 82-94.

[3] V Msomi, S Mabuwa. Analysis of material positioning towards microstructure of the friction stir processed AA1050/AA6082 dissimilar joint. Advances in Industrial and Manufacturing Engineering, 2020, 1: 100002.

[4] XXu, X Ren, $\mathrm{H} \mathrm{Hou}$, et al. Effects of cryogenic and annealing treatment on microstructure and properties of friction stir welded TA15 joints. Materials Science and Engineering A, 2021, 804: 140750.

[5] Y Hu, H Liu, D Li. Contribution of ultrasonic to microstructure and mechanical properties of tilt probe penetrating friction stir welded joint. Journal of Materials Science and Technology, 2021, 85: 205-217.

[6] V Karami, B M Dariani, R Hashemi. Investigation of forming limit curves and mechanical properties of 316 stainless steel/St37 steel tailorwelded blanks produced by tungsten inert gas and friction stir welding method. CIRP Journal of Manufacturing Science and Technology, 2021, 32: 437-446.

[7] R Padmanaban, V Balusamy, V R aira Vignesh. Effect of friction stir welding process parameters on the tensile strength of dissimilar aluminum alloy AA2024-T3 and AA7075-T6 joints. Materialwissenschaft Und Werkstofftechnik, 2020, 51(1): 17-27.

[8] D G Mohan, S Gopi. Influence of In-situ induction heated friction stir welding on tensile, microhardness, corrosion resistance and microstructural properties of martensitic steel. Engineering Research Express, 2021, 3(2): 025023.

[9] O Abedini, E Ranjbarnodeh, P Marashi. Effect of tool geometry and welding parameters on the microstructure and static strength of the friction-stir spot-welded DP780 dual-phase steel sheets. Materiali in Tehnologije, 2017, 51(4): 687-694.

[10] D Avula, V Devuri, M Cheepu, et al. Tensile properties of friction stir welded joints of AA 2024-T6 alloy at different welding speeds. IOP Conference Series: Materials Science and Engineering, 2018, 330(1).

[11] D G Mohan, S Gopi, A Sasikumar. Examining the mechanical and metallurgical properties of single pass friction stir welded dissimilar aluminium alloys Tee joints. SVOA Materials Science \&Technology, 2021, 3(1): 6-12.

[12] C R Renjith, Raghupathy R, D G Mohan. Optimization of process parameters for friction stir lap welding of AA6061-T6 and AA7075-T6 aluminum alloys using Taguchi technique. IJRTS, 2016, 3(4):2348-1439.

[13] L Selvarajan, R Sasikumar, D G Mohan, et al. Investigations on electrochemical machining (ECM) of Al7075 material using the copper electrode for improving geometrical tolerance. Materials Today: Proceedings, 2019, 27: 2708-2712.

[14] L Selvarajan, R Rajavel, B Prakash, et al. Investigation on spark electrical discharge machining of $\mathrm{Si}_{3} \mathrm{~N}_{4}$ based advanced conductive ceramic composites. Materials Today: Proceedings, 2019, 27: 2174-2178.

[15] D G Mohan, S Gopi. A review on friction stir welded T-joint. IJSTE - International Journal of Science Technology \& Engineering, 2016, 2(07): 40-45.
[16] D G Mohan, S Gopi. Induction assisted friction stir welding: A review. Australian Journal of Mechanical Engineering, 2020, 18(1): 119-123.

[17] L Cui, C Zhang, Y Liu. Recent progress in friction stir welding tools used for steels. J. Iron Steel Res. Int., 2018, 25: 477-486.

[18] D G Mohan, S Gopi, V Rajasekar. Effect of induction heated friction stir welding on corrosive behaviour, mechanical properties and microstructure of AISI 410 stainless steel. Indian Journal of Engineering and Materials Sciences, 2018, 25(3): 203-208.

[19] H Fujii, L Cui, K Nakata. Mechanical properties of friction stir welded carbon steel joints - Friction stir welding with and without transformation. Weld World, 2008, 52: 75-81.

[20] E Reza, M Rabby, K Ross, et al. Solid-state joining of thick-section dissimilar materials using a new friction stir dovetailing (FSD) process. Minerals, Metals and Materials Series, 2017, 9783319523828: 67-77.

[21] A I Álvarez, M García, G Pena, et al. Evaluation of an induction-assisted friction stir welding technique for super duplex stainless steels. Surface and Interface Analysis, 2014, 46(10-11): 892-896.

[22] A Sasikumar, S Gopi, D G Mohan. Effect of welding speed on mechanical properties and corrosion resistance rates of filler induced friction stir welded AA6082 and AA5052 joints. Mater. Res. Express, 2021, 8(6): 066531.

[23] A Sasikumar, S Gopi, D G Mohan. Effect of magnesium and chromium fillers on the microstructure and tensile strength of friction stir welded dissimilar aluminium alloys. Materials Research Express, 2019, 6(8).

[24] N A Muhammad, C Wu, G K Padhy. Review: Progress and trends in ultrasonic vibration assisted friction stir welding. Journal of Harbin Institute of Technology (New Series), 2018, 25(3): 16-42.

[25] P Xue, X Zhang, L Wu, et al. Research progress on friction stir welding and processing. Acta Metallurgica Sinica, 2016, 52(10): 1222-1238.

[26] Y Zhang, Y S Sato, H Kokawa, et al. Stir zone microstructure of commercial purity titanium friction stir welded using PCBN tool. Mater. Sci. Eng.-Lausanne- A, 2008, 488(1-2): 25-30.

[27] B Mortazavi, G Cuniberti. Mechanical properties of polycrystalline boron-nitride nanosheets. RSC Advances, 2014, 4(37): 19137-19143.

[28] M A Siddiqui, S Jafri, P Bharti, et al. Friction stir welding as a joining process through modified conventional milling machine: A review. International Journal of Innovative Research \& Development, 2014, 3(7): 149-153.

[29] G K Padhy, C S Wu, S Gao. Auxiliary energy assisted friction stir welding - Status review. Science and Technology of Welding and Joining, 2015, 20(8): 631-649.

[30] M Imam, R Ueji, H Fujii. Effect of online rapid cooling on microstructure and mechanical properties of friction stir welded medium carbon steel. Journal of Materials Processing Technology, 2016, 230: 62-71.

[31] Y M Hwang, C H Lin. Friction stir welding of dissimilar metal sheets. Steel Research International, 2010, 81(9): 1076-1079.

[32] A Mishra. A review on the effect of cryogenic treatment on the mechanical properties of friction stir welded joints. Journal of Advanced Research in Mechanical Engineering and Technology, 2019, 5(3-4): 24-27.

[33] K K Jangra, N Sharma, R Khanna, et al. An experimental investigation and optimization of friction stir welding process for AA6082 T6 (cryogenic treated and untreated) using an integrated approach of Taguchi, grey relational analysis and entropy method. Proceedings of the Institution of Mechanical Engineers, Part L: Journal of Materials: Design and Applications, 2016, 230(2): 454-469.

[34] P Baillie, SW Campbell, A M Galloway, et al. Friction stir welding of $6 \mathrm{~mm}$ thick carbon steel underwater and in air. Science and Technology of Welding and Joining, 2015, 20(7): 585-593.

[35] A Banik, J D Barma, R Singh, et al. A study on the effect of varying revolution pitch for different tool design: Friction stir welding of AA 6061-T6. In: K Shanker, R Shankar, R Sindhwani, eds. Advances in industrial and production engineering. Lecture Notes in Mechanical Engineering, Springer, Singapore, 2019.

[36] L N Brewer, M S Bennett, B W Baker, et al. Characterization of residual stress as a function of friction stir welding parameters in oxide dispersion strengthened (ODS) steel MA956. Materials Science and Engineering: A, 2015, 647: 313-321.

[37] H Dawson, M Serrano, S Cater, et al. Residual stress distribution in friction stir welded ODS steel measured by neutron diffraction. Journal of Materials Processing Technology, 2017, 246: 305-312. 
[38] H Dawson, M Serrano, R Hernandez, et al. Mechanical properties and fracture behaviour of ODS steel friction stir welds at variable temperatures. Materials Science and Engineering: A, 2017, 693: 84-92

[39] A K Lakshminarayanan, V Balasubramanian. Characteristics of laser beam and friction stir welded AISI 409M ferritic stainless steel joints. Journal of Materials Engineering and Performance, 2012, 21(4): 530-539.

[40] TWang, M Komarasamy, S Shukla, et al. Simultaneous enhancement of strength and ductility in an AlCoCrFeNi2.1 eutectic high-entropy alloy via friction stir processing. Journal of Alloys and Compounds, 2018, 766: 312-317.

[41] A Tribe, TW Nelson. Study on the fracture toughness of friction stir welded API X80. Engineering Fracture Mechanics, 2015, 150: 58-69.

[42] M Esmailzadeh, M Shamanian, A Kermanpur, et al. Microstructure and mechanical properties of friction stir welded lean duplex stainless steel. Materials Science and Engineering: A, 2013, 561: 486-491.

[43] J Jeon, S Mironov, Y S Sato, et al. Anisotropy of structural response of single crystal austenitic stainless steel to friction stir welding. Acta Materialia, 2013, 61(9): 3465-3472.

[44] Y C Chen, H Fujii, TTsumura, et al. Banded structure and its distribution in friction stir processing of $316 \mathrm{~L}$ austenitic stainless steel. Journal of Nuclear Materials, 2012, 420(1-3).

[45] A K Lakshminarayanan, V Balasubramanian. Assessment of sensitization resistance of AISI 409M grade ferritic stainless steel joints using modified Strauss test. Materials \& Design, 2012, 39: 175-185.

[46] D M Sekban, S M Aktarer, P Xue, et al. Impact toughness of friction stir processed low carbon steel used in shipbuilding. Materials Science and Engineering: A, 2016, 672: 40-48.

[47] Y Sun, H Fujii, H Imai, et al. Suppression of hydrogen-induced damage in friction stir welded low carbon steel joints. Corrosion Science, 2015, 94: 88-98.

[48] S A Khodir, Y Morisada, R Ueji, et al. Microstructures and mechanical properties evolution during friction stir welding of SK4 high carbon steel alloy. Materials Science and Engineering: A, 2012, 558: 572-578.

[49] D H Choi, C Y Lee, BW Ahn, et al. Hybrid friction stir welding of highcarbon steel. Journal of Materials Science \& Technology, 2011, 27(2): 127-130.

[50] M Abbasi, TW Nelson, C D Sorensen, et al. An approach to prior austenite reconstruction. Materials Characterization, 2012, 66: 1-8.

[51] Y Gao, K Nakata, K Nagatsuka, et al. Interface microstructural control by probe length adjustment in friction stir welding of titanium and steel lap joint. Materials \& Design, 2015, 65: 17-23.

[52] F C Liu, J Liao, Y Gao, et al. Influence of texture on strain localization in stir zone of friction stir welded titanium. Journal of Alloys and Compounds, 2015, 626: 304-308.

[53] Y Morisada, H Fujii, Y Kawahito, et al. Three-dimensional visualization of material flow during friction stir welding by two pairs of $X$-ray transmission systems. Scripta Materialia, 2011, 65(12): 1085-1088.

[54] F C Liu, P Xue, Z Y Ma. Microstructural evolution in recrystallized and unrecrystallized $\mathrm{Al}-\mathrm{Mg}-\mathrm{Sc}$ alloys during superplastic deformation Materials Science and Engineering: A, 2012, 547: 55-63.

[55] F C Liu, ZY Ma. Superplasticity governed by effective grain size and its distribution in fine-grained aluminum alloys. Materials Science and Engineering: A, 2011, 530: 548-558.

[56] F C Liu, TW Nelson. In-situ material flow pattern around probe during friction stir welding of austenitic stainless steel. Materials \& Design, 2016, 110: 354-364

[57] TW Nelson, S A Rose. Controlling hard zone formation in friction stir processed HSLA steel. Journal of Materials Processing Technology, 2016 231: 66-74

[58] R Rai, A De, H K D H Bhadeshia, et al. Review: Friction stir welding tools. Science and Technology of Welding and Joining, 2011, 16(4): 325-342.

[59] $\mathrm{H} \mathrm{H}$ Cho, H N Han, ST Hong, et al. Microstructural analysis of friction stir welded ferritic stainless steel. Materials Science and Engineering A, 2011, 528(6): 2889-2894.

[60] X Fei, J Li, W Yao, et al. Study of temperature on microstructure and mechanical properties on Fe/Al joint in laser-assisted friction stir welding. AlP Advances, 2018, 8(7).

[61] D Du, R Fu, Y Li, et al. Gradient characteristics and strength matching in friction stir welded joints of Fe-18Cr-16Mn-2Mo-0.85N austenitic stainless steel. Materials Science and Engineering A, 2014, 616: 246-251.
[62] O O Tinubu, S Das, A Dutt, et al. Friction stir processing of A-286 stainless steel: Microstructural evolution during wear. Wear, 2016, 356-357: 94-100.

[63] S Mironov, Y S Sato, H Kokawa, et al. Structural response of superaustenitic stainless steel to friction stir welding. Acta Materialia, 2011, 59(14): $5472-5481$

[64] H H Cho, S H Kang, S H Kim, et al. Microstructural evolution in friction stir welding of high-strength linepipe steel. Materials and Design, 2012, 34: $258-267$.

[65] M Imam, V Racherla, K Biswas, et al. Microstructure-property relation and evolution in friction stir welding of naturally aged 6063 aluminium alloy. The International Journal of Advanced Manufacturing Technology, 2017, 91(5-8):1753-1769.

[66] JW Sowards, T Gnäupel Herold, J David McColskey, et al. Characterization of mechanical properties, fatigue-crack propagation, and residual stresses in a microalloyed pipeline-steel friction-stir weld. Materials \& Design, 2015, 88: 632-642.

[67] Y G Kim, J S Kim, I J Kim. Effect of process parameters on optimum welding condition of DP590 steel by friction stir welding. Journal of Mechanical Science and Technology, 2014, 28(12): 5143-5148.

[68] KChiteka. Friction stir welding of steels: A review paper. IOSR Journal of Mechanical and Civil Engineering, 2013, 9(3): 16-20.

[69] S A Hussein, A S M Tahir, A B Hadzley. Characteristics of aluminumto-steel joint made by friction stir welding: A review. Materials Today Communications, 2015, 5: 32-49.

[70] Z Ma, Q Shang, D Ni, et al. Friction stir welding of magnesium alloys: A review. Acta Metallurgica Sinica, 2018, 54(11).

[71] A Banik, B S Roy, J D Barma, et al. An experimental investigation of torque and force generation for varying tool tilt angles and their effects on microstructure and mechanical properties: friction stir welding of AA 6061-T6. J. Manuf. Process, 2018, 31: 395-404.

[72] $X$ Fei, $X$ Jin, Y Ye, et al. Effect of pre-hole offset on the property of the joint during laser-assisted friction stir welding of dissimilar metals steel and aluminum alloys. Materials Science and Engineering A, 2016, 653: 43-52.

[73] S L Campanelli, G Casalino, C Casavola, et al. Analysis and comparison of friction stir welding and laser assisted friction stir welding of aluminum alloy. Materials, 2013, 6(12): 5923-5941.

[74] M K Kulekci, U Esme, B Buldum. Critical analysis of friction stir-based manufacturing processes. International Journal of Advanced Manufacturing Technology, 2016, 85(5-8): 1687-1712.

[75] W J Arbegast. Using process forces as a statistical process control tool for friction stir welds. Proceedings of the Friction Stir Welding and Processing III, TMS Annual Meeting, San Francisco, CA, USA, 2005: 193-204.

[76] X Fei, X Jin, N Peng, et al. Effects of filling material and laser power on the formation of intermetallic compounds during laser-assisted friction stir butt welding of steel and aluminum alloys. Applied Physics A: Materials Science and Processing, 2016, 122(11): 1-10.

[77] P Biswas, N R Mandal. A study on laser assisted friction stir welding of C-Mn steel plates. Advances in Marine Structures - Proceedings of the 3rd International Conference on Marine Structures, MARSTRUCT 2011, March, 2011: 539-548

[78] X Fei, Y Ye, L Jin, et al. Special welding parameters study on Cu/Al joint in laser-heated friction stir welding. Journal of Materials Processing Technology, 2018, 256: 160-171.

[79] Y Hu, H Liu, H Fujii. Improving the mechanical properties of 2219-T6 aluminum alloy joints by ultrasonic vibrations during friction stir welding. Journal of Materials Processing Technology, 2019, 271:75-84.

[80] J Zhao, F Jiang, H Jian, et al. Comparative investigation of tungsten inert gas and friction stir welding characteristics of $\mathrm{Al}-\mathrm{Mg}-\mathrm{Sc}$ alloy plates. Materials \& Design, 2010, 31(1): 306-311.

[81] S J Vijay, N Murugan. Influence of tool pin profile on the metallurgical and mechanical properties of friction stir welded Al-10 wt.\% TiB2 metal matrix composite. Mater. Des., 2010, 31: 3585-3589.

[82] G Casalino, S Campanelli, A D Ludovico, et al. Study of a fiber laser assisted friction stir welding process. High power laser materials processing: Lasers, beam delivery, diagnostics, and applications, 2012, 8239: 823913.

[83] H Potluri, J J Jones, L Mears. Comparison of electrically-assisted and conventional friction stir welding processes by feed force and torque. ASME 2013 International Manufacturing Science and Engineering 
Conference Collocated with the 41st North American Manufacturing Research Conference, MSEC 2013, 2013, 1:1-10.

[84] Y F Sun, Y Konishi, M Kamai, et al. Microstructure and mechanical properties of $\mathrm{S} 45 \mathrm{C}$ steel prepared by laser-assisted friction stir welding. Materials and Design, 2013, 47: 842-849.

[85] DG Mohan, S Gopi, V Rajasekar. Mechanical and corrosion-resistant properties of hybrid-welded stainless steel. Materials Performance, 2018, 57(1): 53-56.

[86] B Ahmad, A Galloway, A Toumpis. Numerical optimization of laser assisted friction stir welding of structural steel. Science and Technology of Welding and Joining, 2019, 24(6): 548-558.

[87] M Wiechec, B Baker, T McNelley, et al. Analysis of high-power diode laser heating effects on $\mathrm{HY}-80$ steel for laser assisted friction stir welding applications. World Journal of Engineering and Technology, 2017, 5(1): 97-112.

[88] F Khodabakhshi, A P Gerlich, A Simchi, et al. Cryogenic friction-stir processing of ultrafine-grained $\mathrm{Al}-\mathrm{Mg}-\mathrm{TiO} 2$ nanocomposites. Materials Science \& Engineering A, 2015, 620: 471-482.

[89] D G Hattingh, C Blignault, T I VanNiekerk, et al. Characterization of the influences of FSW tool geometry on welding forces and weld tensile strength using an instrumented tool. J. Mater. Process Technol., 2008, 203: 46-57.

[90] G Casalino, S L Campanelli, N Contuzzi, et al. Laser-assisted friction stir welding of aluminum alloy lap joints: microstructural and microhardness characterizations. High-Power Laser Materials Processing: Lasers, Beam Delivery, Diagnostics, and Applications III, 2014, 8963: 896316.

[91] C Yang, J F Zhang, G N Ma, et al. Microstructure and mechanical properties of double-side friction stir welded 6082Al ultra-thick plates. Journal of Materials Science \& Technology, 2020, 41:105-116.

[92] G K Padhy, C S Wu, S Gao. Friction stir based welding and processing technologies - processes, parameters, microstructures and applications: A review. Journal of Materials Science \& Technology, 2018, 34(1): 1-38.

[93] Q Chu, WY Li, H L Hou, et al. On the double-side probeless friction stir spot welding of AA2198 Al-Li alloy. Journal of Materials Science \& Technology, 2019, 35(5): 784-789.

[94] H Zhang, P Xue, D Wang, et al. Effect of heat-input on pitting corrosion behavior of friction stir welded high nitrogen stainless steel. Journal of Materials Science \& Technology, 2019, 35(7): 1278-1283.

[95] Z Zhang, C He, Y Li, et al. Effects of ultrasonic assisted friction stir welding on flow behavior, microstructure and mechanical properties of 7N01-T4 aluminum alloy joints. Journal of Materials Science \& Technology, 2020, 43: 1-13.

[96] Q Chu, WY Li, XW Yang, et al. Microstructure and mechanical optimization of probeless friction stir spot welded joint of an Al-Li alloy. Journal of Materials Science \& Technology, 2018, 34(10): 1739-1746.

[97] R Z Xu, Q Yang, D R Ni, et al. Influencing mechanism of pre-existing nanoscale Al5Fe2 phase on $\mathrm{Mg}$-Fe interface in friction stir spot welded Al-free ZK60-Q235 joint. Journal of Materials Science \& Technology, 2020, 42: 220-228.

[98] Z Ma, Y Jin, S Ji, X Meng, et al. A general strategy for the reliable joining of $\mathrm{Al} / \mathrm{Ti}$ dissimilar alloys via ultrasonic assisted friction stir welding. Journal of Materials Science \& Technology, 2019, 35(1): 94-99.

[99] F Fujii, Y D Chung, Y F Sun. Friction stir welding of AISI 1080 steel using liquid $\mathrm{CO} 2$ for enhanced toughness and ductility. Science and Technology of Welding and Joining, 2013, 18(6): 500-506.

[100] M X Milagre, U Donatus, N V Mogili, et al. Galvanic and asymmetry effects on the local electrochemical behavior of the 2098-T351 alloy welded by friction stir welding. Journal of Materials Science \& Technology, 2020, 45: 162-175.

[101] XWang, Y Morisada, H Fujii. Flat friction stir spot welding of low carbon steel by double side adjustable tools. Journal of Materials Science \& Technology, 2021, 66: 1-9.

[102] $\mathrm{W} \mathrm{Hu}, \mathrm{Z} \mathrm{Ma}$, S Ji, et al. Improving the mechanical property of dissimilar $\mathrm{Al} / \mathrm{Mg}$ hybrid friction stir welding joint by PIO-ANN. Journal of Materials Science \& Technology, 2020, 53: 41-52.

[103] M Esmaily, N Mortazavi, W Osikowicz, et al. Bobbin and conventional friction stir welding of thick extruded AA6005-T6 profiles. Materials and Design, 2016, 108: 114-125.

[104] Y Morisada, H Fujii, R Nishimoto, et al. Improvement of toughness and strength of thick structural steel weld by friction stir welding conditions. Science and Technology of Welding and Joining, 2013, 18(4): 287-292.
[105] D G Mohan, S Gopi. Study on the mechanical behaviour of friction stir welded aluminium alloys 6061 with 5052. 2017 8th Industrial Automation and Electromechanical Engineering Conference, IEMECON 2017, 2017: 147-152.

[106] P L Niu, WY Li, A Vairis, et al. Cyclic deformation behavior of friction-stirwelded dissimilar AA5083-to-AA2024 joints: Effect of microstructure and loading history. Materials Science and Engineering A, 2019, 744: $145-153$.

[107] S Shashi Kumar, N Murugan, K K Ramachandran. Identifying the optimal FSW process parameters for maximizing the tensile strength of friction stir welded AISI 316L butt joints. Measurement: Journal of the International Measurement Confederation, 2019, 137: 257-271.

[108] S S Kumar, N Murugan, K K K Ramachandran. Effect of tool tilt angle on weld joint properties of friction stir welded AISI 316L stainless steel sheets. Measurement, 2020, 150: 107083.

[109] K M Venkatesh, M Arivarsu, M Manikandan, et al. Review on friction stir welding of steels. Materials Today: Proceedings, 2018, 5(5): 13227-13235.

[110] S Gopi, D G Mohan. Evaluating the welding pulses of various tool profiles in single-pass friction stir welding of 6082-T6 aluminium alloy. Journal of Welding and Joining, 2021, 8.

[111] M Jariyaboon, A J Davenport, R Ambat, et al. Effect of cryogenic cooling on corrosion of friction stir welded AA7010-T7651. Anti-Corrosion Methods and Materials, 2010, 57(2): 83-89.

[112] YYWang, R Kannan, L Li, et al. Polarization effects associated with thermal processing of $\mathrm{HY}-80$ structural steel using high-power laser diode array. Science and Technology of Welding and Joining, 2013, 1718(12): $1-10$.

[113] Y S Sato, M Fujimoto, N Abe, et al. Friction stir spot welding phenomena in Al alloy 6061. Materials Science Forum, 2010, 638-642(2): 1243-1248.

[114] B T Gibson, D H Lammlein, T J Prater, et al. Friction stir welding: Process, automation, and control. Journal of Manufacturing Processes, 2014, 16(1): $56-73$.

[115] PF Mendez, N Barnes, K Bell, et al. Welding processes for wear resistant overlays. Journal of Manufacturing Processes, 2014, 16(1): 4-25.

[116] ST Selvamani. Heat transfer analysis during friction stir welding of Al6061-T6 alloy. International Journal of Engineering Research and Applications (IJERA), 2014, 1(4): 1453-1460.

[117] K Colligan. Material flow behavior during friction stir welding of aluminum. Welding Journal (Miami, Fla), 1999, 78(7): 229-s.

[118] ESAB. Technical hand book: Friction stir welding. Global Welding \& Cutting, 2009: 1-45.

[119] J J Muhsin, M H Tolephih, A M Muhammed. Effect of friction stir welding parameters (rotation and transverse) speed on the transient temperature distribution in friction stir welding of AA 7020-t53. ARPN Journal of Engineering and Applied Sciences, 2012, 7(4): 436-446.

[120] R S Mishra, ZY Ma. Friction stir welding and processing. Materials Science and Engineering R: Reports, 2005, 50(1-2): 1-78.

[121] J Lukkari, O Vähäkainu. How much heat can various steels and filler metals withstand? Svetsaren, a Welding Review, 2003, 58(1): 18-23.

[122] G Buffa, L Fratini, S Pasta. Residual stresses in friction stir welding: Numerical simulation and experimental verification. Powder Diffraction, 2008, 23(2): 182-182.

[123] M Imam, Y Sun, H Fujii. Interface controlled plastic flow using accelerated cooling in friction stir welding of pure iron. National Meetings of JWS, June 30, 2017.

[124] Q Yang, X Li, K Chen, et al. Effect of tool geometry and process condition on static strength of a magnesium friction stir lap linear weld. Mater. Sci. Eng. A, 2011, 528: 2463-2478.

[125] C Sorensen, T Nelson. Friction stir welding of ferrous and nickel alloys. Friction Stir Welding and Processing, 2007: 111-121.

[126] A De, H K D H Bhadeshia, T Debroy. Friction stir welding of mild steel: Tool durability and steel microstructure. Materials Science and Technology (United Kingdom), 2014, 30(9): 1050-1056.

[127] M Al Moussawi, A J Smith. Defects in friction stir welding of steel. Metallography, Microstructure, and Analysis, 2018, 7(2): 194-202.

[128] A K Lakshminarayanan, V Balasubramanian. Understanding the parameters controlling friction stir welding of AISI $409 \mathrm{M}$ ferritic stainless steel. Met. Mater. Int., 2011, 17(6): 969-998.

[129] S Ryan, A Toumpis, A Galloway, Defect tolerance of friction stir welds in DH36 steel. Mater. Des., 2015, 87(15): 701-711. 
[130] W J Arbegast. A flow-partitioned deformation zone model for defect formation during friction stir welding. Scripta Materialia, 2008, 58(5): 372-376.

[131] R Ranjan, A R Khan, C Parikh, et al. Classification and identification of surface defects in friction stir welding: An image processing approach Journal of Manufacturing Processes, 2016, 22: 237-253.

[132] A Toumpis, A Gallawi, H Polezhayeva, et al. Fatigue assessment of friction stir welded DH36 steel. Frict. Stir Weld. Process VIII, 2015, 11-19.

[133] M Almoussawi, A J Smith, M Faraji, et al. Segregation of Mn, Si, Al, and oxygen during the friction stir welding of DH36 steel. Metallogr. Microstruct. Anal., 2017, 6: 569 .

[134] P Gong, E J Palmiere, W M Rainforth. Dissolution and precipitation behaviour in steels microalloyed with niobium during thermomechanical processing. Acta Mater., 2015, 97: 392-403.

[135] A B Santillana, R Boom, D Eskin, et al. High-temperature mechanical behaviour and fracture analysis of a low-carbon steel related to cracking, Metallurgical and Materials Transactions A, 2012, 43A: 5048-5057.

[136] M Hajizadeh, S Emami, T Saeid. Influence of welding speed on microstructure formation in friction-stir-welded 304 austenitic stainless steels. Int. J. Miner. Metall. Mater., 2020, 27: 1517-1524.

[137] X C Liu, Y F Sun, T Nagira, et al. Strain rate dependent micro-texture evolution in friction stir welding of copper. Materialia, 2019, 6: 100302

[138] M W Safeen, P Russo Spena. Main issues in quality of friction stir welding joints of aluminum alloy and steel sheets. Metals, 2019, 9(5).

[139] S A Hussein, S Thiru, R Izamshah, et al. Unstable temperature distribution in friction stir welding. Advances in Materials Science and Engineering, 2014: 980636

[140] M M Z Ahmed, B P Wynne, M M El Sayed Seleman, et al. A comparison of crystallographic texture and grain structure development in aluminum generated by friction stir welding and high strain torsion, Mater. Des., 2016, 103: 259

[141] S Emami, T Saeid, R A Khosroshahi, Microstructural evolution of friction stir welded SAF 2205 duplex stainless steel. J. Alloys Compd., 2018, 739: 678.

[142] L Wan, Y Huang. Friction stir welding of dissimilar aluminum alloys and steels: a review. Int. J. Adv. Manuf. Technol., 2018, 99: 1781-1811.

[143] W M Yan, Z Q Xie, C Yu, et al. Experimental investigation and design method for the shear strength of self-piercing rivet connections in thinwalled steel structures. J. Construc. Steel Res., 2017, 133: 231-240.

[144] L A Jácome, S Weber, A Leitner, et al. Influence of filler composition on the microstructure and mechanical properties of steel-aluminum joints produced by metal arc joining. Adv. Eng. Mater., 2009, 11(5): 350-358.

[145] P K Baghel. Friction stir welding of stainless steel 304: A survey. IOSR Journal of Mechanical and Civil Engineering, 2012, 1(2): 22-23.

[146] F C Liu, Y Hovanski, M P Miles, et al. A review of friction stir welding of steels: Tool, material flow, microstructure, and properties, J. Mater. Sci. Technol., 2018, 34(1): 39-57.

[147] J C Ananad, S Gopi, D G Mohan. Predicting the ultimate tensile strength and wear rate of aluminium hybrid surface composites fabricated via friction stir processing using computational methods. Journal of Adhesion Science and Technology, 2021: 1-20.

[148] M Balamurugan, S Gopi, D G Mohan. Influence of tool pin profiles on the filler added friction stir spot welded dissimilar aluminium alloy joints. Materials Research Express, 2021, 8(9): 96531.

[149] M Magnani, M Terada, A O Lino, et al. Microstructural and electrochemical characterization of friction stir welded duplex stainless steels. International Journal of Electrochemical Science, 2014, 9(6): 2966-2977.

[150] A Janeczek, J Tomków, D Fydrych. The influence of tool shape and process parameters on the mechanical properties of AW-3004 aluminium alloy friction stir welded joints. Materials, 2021, 14(12).

[151] H L Qin, H Zhang, D T Sun, et al. Corrosion behavior of the frictionstir-welded joints of 2A14-T6 aluminum alloy. International Journal of Minerals, Metallurgy and Materials, 2015, 22(6): 627-638.

[152] A Astarita, M Curioni, A Squillace, et al. Corrosion behaviour of stainless steel-titanium alloy linear friction welded joints: Galvanic coupling. Materials and Corrosion, 2015, 66(2): 111-117.

[153] M Atapour, H Sarlak, M Esmailzadeh. Pitting corrosion susceptibility of friction stir welded lean duplex stainless steel joints. International Journal of Advanced Manufacturing Technology, 2016, 83(5-8): 721-728.

[154] P Goel, A W Mohd, N Sharma, et al. Effects of welding parameters in friction stir welding of stainless steel and aluminum. In: K Shanker,
R Shankar, R Sindhwani, eds. Advances in industrial and production engineering. Lecture Notes in Mechanical Engineering, 2019.

[155] M Dadfar, M H Fathi, F Karimzadeh, et al. Effect of TIG welding on corrosion behavior of 316L stainless steel. Materials Letters, 2007, 61(11-12): 2343-2346

[156] R Rafiei, A Ostovari Moghaddam, M R Hatami, et al. Microstructural characteristics and mechanical properties of the dissimilar friction-stir butt welds between an Al-Mg alloy and A316L stainless steel. Int. J. Adv. Manuf. Technol., 2017, 90(9-12): 2785-2801.

[157] X Geng, H Feng, Z Jiang, et al. Microstructure, mechanical and corrosion properties of friction stirwelding high nitrogen martensitic stainless steel 30Cr15Mo1N. Metals, 2016, 6(12): 1-14.

[158] G R Mohammed, M Ishak, S N Aqida, et al. Effects of heat input on microstructure, corrosion and mechanical characteristics of welded austenitic and duplex stainless steels: A review. Metals, 2017, 7(2).

[159] S HC Park, Y S Sato, H Kokawa, et al. Corrosion resistance of friction stir welded 304 stainless steel. Scripta Materialia, 2004, 51(2): 101-105.

[160] American Iron and Steel Institute. Welding of stainless steels and other joining methods. A Designers' Handbook Series, 2016, 9002: 1-46.

[161] T G Gooch. Corrosion behavior of welded stainless steel. Welding Journal (Miami, Fla), 1996, 75(5): 135-s.

[162] M Jayaraman, R Sivasubramanian, V Balasubramanian, et al. Optimization of process parameters for friction stir welding of cast aluminium alloy A319 by Taguchi method. Journal of Scientific and Industrial Research, 2009, 68(1): 36-43.

[163] D G Mohan, S Gopi, J Tomkow. Induction assisted hybrid friction stir welding of dissimilar materials Aa5052 aluminium alloy and $\mathrm{X} 12 \mathrm{Cr} 13$ stainless steel. Advances in Materials Science, 2021, 21(3).

[164] H Sarlak, M Atapour, M Esmailzadeh. Corrosion behavior of friction stir welded lean duplex stainless steel. Materials and Design, 2015, 66: 209-216.

[165] M P Meshram, B K Kodli, S R Dey. Friction stir welding of austenitic stainless steel by PCBN tool and its joint analyses. Procedia Materials Science, 2014, 6: 135-139.

[166] J Wang, R Fu, Y Li, et al. Effects of deep cryogenic treatment and lowtemperature aging on the mechanical properties of friction-stir-welded joints of 2024-T351 aluminum alloy. Materials Science and Engineering A, 2014, 609: 147-153.

[167] M Almoussawi, A J Smith, M Faraji. Wear of polycrystalline boron nitride tool during the friction stir welding of steel. Metallogr. Microstruct. Anal., 2018, 7: 252-267.

[168] L Shi, C S Wu, H J Liu. Numerical analysis of heat generation and temperature field in reverse dual-rotation friction stir welding. Int. J. Adv. Manuf. Technol., 2014, 74: 319-334.

[169] Y Han, X Jiang, S Chen, et al. Microstructure and mechanical properties of electrically assisted friction stir welded AZ31B alloy joints. Journal of Manufacturing Processes, 2019, 43: 26-34.

[170] M Mahmoudiniya, L A I Kestens. Microstructural development and texture evolution in the stir zone and thermomechanically affected zone of a ferrite-martensite steel friction stir weld. Materials Characterization, 2021, 175: 111053, 2021.

[171] J Kangazian, M Shamanian. Microstructure and mechanical characterization of Incoloy $825 \mathrm{Ni}$-based alloy welded to 2507 super duplex stainless steel through dissimilar friction stir welding. Transactions of Nonferrous Metals Society of China, 2019, 29(8), 1677-1688.

[172] C Cheng, K Kadoi, S Tokita, et al. Effects of carbon and chromium on microstructure evolution and mechanical properties of friction stir weldment in medium-carbon steel. Materials Science and Engineering A, 2019, 762: 138060 .

[173] M Mahmoudiniya, A H Kokabi, M Goodarzi, et al. Friction stir welding of advanced high strength dual phase steel: Microstructure, mechanical properties and fracture behavior. Materials Science and Engineering: $A$, 2020, 769: 138490.

[174] A R Raja, M Vashista, M Z Khan Yusufzai. Estimation of material properties using hysteresis loop analysis in friction stir welded steel plate. Journal of Alloys and Compounds, 2020, 814: 152265.

[175] K Singh, G Singh, H Singh. Review on friction stir welding of magnesium alloys. Journal of Magnesium and Alloys, 2018, 6(4): 399-416.

[176] S J Lee, T M Park, J H Nam, et al. The unexpected stress-strain response of medium Mn steel after friction stir welding. Materials Science and Engineering A, 2019, 744: 340-348. 
[177] P Kaushik, D K Dwivedi. Effect of tool geometry in dissimilar Al-Steel Friction Stir Welding, Journal of Manufacturing Processes, 2021, 68: 198-208.

[178] S Li, X Yang, N Vajragupta, et al. The influence of post-weld tempering temperatures on microstructure and strength in the stir zone of friction stir welded reduced activation ferritic/martensitic steel. Materials Science and Engineering: $A, 2021,814: 141224$.

[179] M Habibnia, M Shakeri, S Nourouzi, et al. Microstructural and mechanical properties of friction stir welded $5050 \mathrm{Al}$ alloy and 304 stainless steel plates. Int. J. Adv. Manuf. Technol., 2015, 76(5-8): 819-829.

[180] M Mahmoudiniya, L A I Kestens. Microstructural development and texture evolution in the stir zone and thermomechanically affected zone of a ferrite-martensite steel friction stir weld. Materials Characterization, 2021, 175: 111053.

[181] Y D Chung, H Fujii, R Ueji, et al. Friction stir welding of high carbon steel with excellent toughness and ductility. Scr. Mater., 2010, 63: 223-226.

[182] KWang, B Wu, K Qiao, et al. Microstructure and mechanical properties of friction stir lap welded dissimilar zirconium-steel joint. Journal of Materials Research and Technology, 2020, 9(6): 15087-15093.

[183] I Das Chowdhury, K Sengupta, D K Singh, et al. Study of mechanical properties of mild steel joint made by electrically assisted friction stir welding using DC and AC. Materials Today: Proceedings, 2021, 44 3959-3966

[184] P L Florence, K S Narayanaswamy, Sai Sesha Talpa, et al. Impact of friction stir welding tool profile on the strength of dissimilar aluminium and stainless steel welded joints. Materials Today: Proceedings, 2020: 10-12.

[185] D Kr Singh, K Sengupta, S Karmakar, et al. Effect of different tool pin diameter on mechanical properties of friction stirred welded AISI 304 stainless steel plate. Materials Today: Proceedings, 2020, 38: 2241-2248.

[186] A Bhatia, R Wattal. Friction stir welding of carbon steel: Effect on microstructure and tensile strength. Materials Today: Proceedings, 2019, 26: 1803-1808.

[187] Q Wu, M Li, Y Guo, et al. Microstructural evolution and mechanical properties of friction stir welded 12Cr-ODS steel. Nuclear Materials and Energy, 2020, 25: 100804.

[188] F Fang, X Hu, B Zhang, et al. Deformation of dual-structure medium carbon steel in cold drawing. Material Science and Engineering A, 2013, 583: 78-83.

[189] H Montazerolghaem, M Badrossamay, A F Tehrani. Investigation of vibration assisted friction stir welding. Key Engineering Materials, 2012, 504-506: 741-746.

[190] A Yazdipour, A Heidarzadeh. Effect of friction stir welding on microstructure and mechanical properties of dissimilar Al 5083-H321 and 316L stainless steel alloy joints. J. Alloys Compd., 2016, 680: 595-603.

[191] M A Wahid, Z A Khan, A N Siddiquee. Review on underwater friction stir welding: a variant of friction stir welding with great potential of improving joint properties. Nonferrous Met. Soc. China, 2018, 28(1): 193-219.

[192] C Cheng, K Kadoi, H Fujii, et al. Improved strength and ductility balance of medium-carbon steel with chromium and titanium fabricated by friction stir welding process. Materials Science and Engineering A, 2021, 803: 140689.

[193] K H Song, T Tsumura, K Nakata. Development of microstructure and mechanical properties in laser-FSW hybrid welded Inconel 600. Materials Transactions, 2009, 50: 1832-1837.

[194] Y Zhao, C Dong, Z Jia, et al. Microstructure characteristics and corrosion resistance of friction stir welded 2205 duplex stainless steel. Advances in Materials Science and Engineering, 2021: 8890274.

[195] G D Q Caetano, C C Silva, M F Motta, et al. Intergranular corrosion evaluation of friction stir welded AISI 410 S ferritic stainless steel. Journal of Materials Research and Technology, 2019, 8(2): 1878-1887.

[196] X Meng, Z Xu, Y Huang, et al. Interface characteristic and tensile property of friction stir lap welding of dissimilar aircraft 2060-T8 and 2099-T83 Al-Li alloys. International Journal of Advanced Manufacturing Technology, 2018, 94(1-4): 1253-1261.

[197] Y Wang, R Kannan, L Li. Characterization of as-welded microstructure of heat-affected zone in modified $9 \mathrm{Cr}-1 \mathrm{Mo}-\mathrm{V}-\mathrm{Nb}$ steel weldment. Materials Characterization, 2016, 118: 225-234.

[198] Y Wang, R Kannan, L Li. Correlation between intercritical heataffected zone and type IV creep damage zone in grade 91 steel.
Metallurgical and Materials Transactions A: Physical Metallurgy and Materials Science, 2018, 49(4): 1264-1275.

[199] L Tan, Y Katoh, A A F Tavassoli, et al. Recent status and improvement of reduced-activation ferriticmartensitic steels for high-temperature service. J. Nucl. Mater., 2016, 479: 515-523.

[200] C Cabet, F Dalle, E Gaganidze, et al. Ferritic-martensitic steels for fission and fusion applications, J. Nucl. Mater., 2019, 523: 510-537.

[201] J J Vora, V J Badheka. Experimental investigation on microstructure and mechanical properties of activated TIG welded reduced activation ferritic/ martensitic steel joints. J. Manuf. Process, 2017, 25: 85-93.

[202] V L Manugula, KV Rajulapati, G M Reddy, et al. Role of evolving microstructure on the mechanical properties of electron beam welded ferriticmartensitic steel in the as-welded and post weld heattreated states. Mater. Sci. Eng. : A, 2017, 698: 36-45.

[203] S Chen, J Huang, Q Lu, et al. Microstructures and mechanical properties of laser welding joint of a CLAM steel with revised chemical compositions. J. Mater. Eng. Perform, 2016, 25(5): 1848-1855.

[204] W M Thomas, P L Threadgill, E D Nicholas. Feasibility of friction stir welding steel. Sci. Technol. Weld. Join., 1999, 4(6): 365-372.

[205] W Tang, J Chen, X Yu, et al. Heat input and post weld heat treatment effects on reduced-Activation ferritic/martensitic steel friction stir welds. Friction Stir Welding and Processing VIII, 2015: 83-87.

[206] V L Manugula, K V Rajulapati, G M Reddy, et al. A critical assessment of the microstructure and mechanical properties of friction stir welded reduced activation ferritic-martensitic steel. Mater. Des., 2016 92: 200-212.

[207] C Zhang, L Cui, C X Liu, et al. Microstructures and mechanical properties of friction stir welds on $9 \% \mathrm{Cr}$ reduced activation ferritic/martensitic steel. J. Mater. Sci. Technol., 2018, 34(5): 756-766.

[208] S Li, X Yang, W Tang, et al. Effect of friction stir processing on microstructure and work hardening behavior of reduced activation ferritic/ martensitic steel. J. Manuf. Process, 2019, 37: 220-231.

[209] C Zhang, L Cui, D P Wang, et al. Effect of microstructures to tensile and impact properties of stir zone on $9 \% \mathrm{Cr}$ reduced activation ferritic/martensitic steel friction stir welds. Mater. Sci. Eng. A, 2018, 729: 257-267.

[210] V L Manugula, KV Rajulapati, G M Reddy, et al. Influence of tool rotational speed and post-weld heat treatments on friction stir welded reduced activation ferritic-martensitic steel, Metall. Mater. Trans. A, 2017, 48(8): 3702-3720

[211] V L Manugula, KV Rajulapati, G M Reddy, et al. Friction stir welding of thick section reduced activation ferritic-martensitic steel. Sci. Technol. Weld. Join., 2018, 23(8): 666-676.

[212] Z Z Yu, Z L Feng, D Hoelzer, et al. Friction stir welding of ODS and RAFM steels. Metall. Mater. Trans., 2015, 2(3): 164-172.

[213] X Li, J Chen, P Hua, et al. Effect of post weld heat treatment on the microstructure and properties of Laser-TIG hybrid welded joints for CLAM steel. Fusion Eng. Des., 2018, 128: 175-181.

[214] M F Ashby. The deformation of plastically non-homogeneous materials. Phil. Mag.: J. Theor. Exp. Appl. Phys., 1970, 21(170): 399-424.

[215] W Pantleon. Resolving the geometrically necessary dislocation content by conventional electron backscattering diffraction. Scripta Mater., 2008, 58(11): 994-997.

[216] C C Eiselt, H Schendzielora, A Seubert, et al. ODS-materials for high temperature applications in advanced nuclear systems. Nucl. Mater. Energy, 2016, 9: 22-28.

[217] Y Ijiri, N Oono, S Uaki, et al. Oxide particle-dislocation interaction in 9Cr-ODS steel. Nucl. Mater. Energy, 2016, 9: 348-382.

[218] C L Chen, G J Tatlock, A R Jones. Microstructural evolution in friction stir welding of nanostructured ODS alloys. J. Alloy. Compd., 2010, 504: 460-466

[219] S Chen, Y Wang, N Hashimoto, et al. Post-irradiation annealing behavior of helium in irradiated Fe and ferriticmartensitic steels. Nucl. Mater. Energy, 2018, 15: 203-207.

[220] T K Kim, S Noh, S H Kang, et al. Development of advanced radiation resistant ODS steel for fast reactor system applications. World. J. Eng. Technol., 2015, 3: 125-128.

[221] J Macías Delgado, T Leguey, V De, et al. Microstructure and tensile properties of ODS ferritic steels mechanically alloyed with Fe2Y. Nucl. Mater. Energy, 2016, 9: 372-377. 
[222] H J Xu, Z Lu, D M Wang, et al. Microstructural evolution in a new Fe based ODS alloy processed by mechanical alloying. Nucl. Mater. Energy, 2016, 7: 1-4.

[223] H Dawson, M Serrano, S Cater, et al. Impact of friction stir welding on the microstructure of ODS steel. J. Nucl. Mater., 2017, 486: 129-137.

[224] S Rogozhkin, A Bogachev, O Korchuganova, et al. Nanostructure evolution in ODS steels under ion irradiation. Nucl. Mater. Energy, 2016, 9: 66-74.

[225] WT Han, P P Liu, X O Yi, et al. Impact of friction stir welding on recrystallization of oxide dispersion strengthened ferritic steel. J. Mater. Sci. Technol., 2018, 34: 209-213.

[226] Y Yano, Y S Sato, Y Sekio, et al. Mechanical properties of friction stir welded 11Cr-ferritic/martensitic steel. J. Nucl. Mater., 2013, 442: 524-528.

[227] WT Han, A Kimura, N Tsuda, et al. Effects of mechanical force on grain structures of friction stir welded oxide dispersion strengthened ferritic steel. J. Nucl. Mater., 2014, 455: 46-50.

[228] H Dawson, M Serrano, S Cater, et al. Characterization of ODS steel friction stir welds and their abnormal grain growth behavior. Fusion Eng. Des., 2018, 56: 174-182.

[229] JYWang, W Yuan, R S Mishra, et al. Microstructural evolution and mechanical properties of friction stir welded ODS alloy MA754. J. Nucl. Mater., 2013, 442: 1-6.

[230] K Yabuuchi, N Tsuda, A Kimura, et al. Effects of tool rotation speed on the mechanical properties and microstructure of friction stir welded ODS steel. Mat. Sci. Eng. A Struct., 2014, 595: 291-296.

[231] WT Han, F R Wan, K Yabuuchi, et al. Joint inhomogeneity in dissimilar friction stir welded martensitic and nanostructured ferritic steels. Sci. Technol. Weld. Joi., 2018, 23: 659-665.

[232] B Mazumder, X Yu, P D Edmondson, et al. Effect of friction stir welding and post-weld heat treatment on a nanostructured ferritic alloy. J. Nucl. Mater., 2016, 469: 200-208.

[233] H Serizawa, H Ogura, Y Morisada, et al. Influence of friction stir welding conditions on joinability of V-alloy/ SUS316L dissimilar joint. Nucl. Mater. Energy, 2018, 15: 43-47.

[234] M H Mathon, V Klosek, Y D Carlan, et al. Study of PM2000 microstructure evolution following FSW process. J. Nucl. Mater., 2009, 386-388: 475-478.

[235] H Serizawa, M Murakami, Y Morisada, et al. Influence of friction stir welding conditions on joinability of oxide dispersion strengthened steel / F82H ferritic/martensitic steel joint. Nucl. Mater. Energy, 2016, 9: 367-371.

[236] Y G G Kim, I J J Kim, J S S Kim, et al. Mechanical properties and tool life of friction-stir-welded DP590 using the Si3N4 tool. Mater. Trans., 2014, 55: 1557-1563.

[237] H Ashrafi, M Shamanian, R Emadi, et al. Comparison of microstructure and tensile properties of dual phase steel welded using friction stir welding and gas tungsten arc welding. Steel Res. Int., 2018, 89: 1-8.

[238] M Al Moussawi, A J Smith, A Young, et al. Modelling of friction stir welding of DH36 steel. Int. J. Adv. Manuf. Technol., 2017.

[239] RW Fonda, K E Knipling, D J Rowenhorst. EBSD analysis of friction stir weld textures. JOM, 2014, 66: 149-155.

[240] M Maalekian, E Kozeschnik, S Chatterjee, et al. Mechanical stabilisation of eutectoid steel. Mater. Sci. Technol., 2007, 23: 610-612.

[241] RW Fonda, K E Knipling. Texture development in friction stir welds, Sci. Technol. Weld. Join., 2011, 16: 288-294.

[242] D Gera, B Fu, U F H R Suhuddin, et al. Microstructure, mechanical and functional properties of refill friction stir spot welds on multilayered aluminum foils for battery application. Journal of Materials Research and Technology, 2021, 13: 2272-2286.

[243] T Sakai, A Belyakov, H Miura. Ultrafine grain formation in Ferritic stainless steel during severe plastic deformation. Metall. Mater. Trans. A, 2008, 39: 2206.

[244] K Huang, R E Log'e. A review of dynamic recrystallization phenomena in metallic materials. Mater. Des., 2016, 111: 548-574.

[245] H S Bang, G H Jeon, I H Oh, et al. Gas tungsten arc welding assisted hybrid friction stir welding of dissimilar materials Al6061-T6 aluminum alloy and STS304 stainless steel. Mater. Des., 2012, 37: 48-55.

[246] S Joo. Joining of dissimilar AZ31B magnesium alloy and SS400 mild steel by hybrid gas tungsten arc friction stir welding. Met. Mater Int., 2013, 19: 1251-1257.
[247] C A Hernández, V H Ferrer, J E Mancilla. Three-dimensional numerical modeling of the friction stir welding of dissimilar steels. Int. J. Adv. Manuf. Technol., 2017, 93: 1567-1581.

[248] X C Liu, Y F Sun, T Nagira, et al. Evaluation of dynamic development of grain structure during friction stir welding of pure copper using a quasi in situ method, J. Mater. Sci. Technol., 2019, 35: 1412-1421.

[249] S Mironov, Y S Sato, H Kokawa. Microstructural evolution during friction stir-processing of pure iron. Acta Mater., 2008, 56: 2602-2614.

[250] M M Husain, R Sarkar, TK Pal, et al. Quantification of microtexture at weld nugget of friction stir-welded carbon steel. J. Mater. Eng. Perform, 2017, 26: 2047-2056.

[251] HI Dawood, K S Mohammed, M Y Rajab. Advantages of the green solid state FSW over the conventional GMAW process. Advances in Materials Science and Engineering, 2014: 105713.

[252] S R McLaughlin, C J Bayley, N M Aucoin. Assessment of microstructural heterogeneities in multipass pulsed gas metal arc welds, Canadian Metallurgical Quarterly, 2012, 51(3): 294-301.

[253] P Kamal, K P Surjya. Effect of pulse parameters on weld quality in pulsed gas metal arc welding: A review. Journal of Materials Engineering and Performance, 2011, 20(6): 918-931.

[254] T Saeid, A Abdollah Zadeh, T Shibayanagi, et al. On the formation of grain structure during friction stir welding of duplex stainless steel. Mater. Sci. Eng. A, 2010, 527: 6484-6488.

[255] S Emami, S Sadeghi Kanani, T Saeid. Dissimilar friction stir welding of AISI 430 ferritic and AISI 304L austenitic stainless steels. Archiv. Civ. Mech. Eng., 2020, 20: 131.

\section{Submit your manuscript to a SpringerOpen ${ }^{\circ}$ journal and benefit from:}

- Convenient online submission

- Rigorous peer review

- Open access: articles freely available online

- High visibility within the field

- Retaining the copyright to your article

Submit your next manuscript at springeropen.com 